NBSIR 84-2901

\title{
Relationships Between Mechanical Properties and Performance of Inks as the Basis for Quality Control Techniques: Part II
}

Donald L. Hunston and George W. Bullman

U.S. DEPARTMENT OF COMMERCE

National Bureau of Standards

Polymers Division

Gaithersburg, MD 20899

January 1984

Issued November 1984

Prepared for

U.S. Department of Treasury

Bureau of Engraving and Printing

Department of Research and Technical Services

Washington, DC 20226 

NBSIR 84-2901

RELATIONSHIPS BETWEEN MECHANICAL

PROPERTIES AND PERFORMANCE OF

INKS AS THE BASIS FOR QUALITY

CONTROL TECHNIQUES: PART II

Donald L. Hunston and George W. Bullman

U.S. DEPARTMENT OF COMMERCE

National Bureau of Standards

Polymers Division

Gaithersburg, MD 20899

January 1984

Issued November 1984

Prepared for

U.S. Department of Treasury

Bureau of Engraving and Printing

Department of Research and Technical Services

Washington, DC 20226

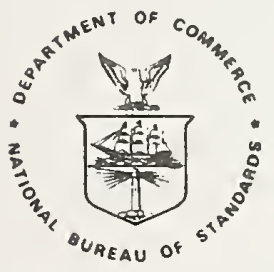

U.S. DEPARTMENT OF COMMERCE, Malcolm Baldrige, Secretary NATIONAL BUREAU OF STANDARDS, Ernest Ambler, Director 
RELATIONSHIPS BETWEEN MECHANICAL PROPERTIES AND PERFORMANCE OF INKS AS THE BASIS FOR QUALITY CONTROL TECHNIQUES: PART II

\begin{abstract}
ABESTRACT
This report reviews the progress of a joint program with the Bureau of Engraving and Printing (BEP) designed to study the mechanical properties of ink both before and during curing. The objectives are to develop quality control tests and guidelines for improved ink formulations. This report covers progress in a number of 5 pecific research areas. First, the development of a new cure test using a rubber mill to simulate some conditions on the press is discussed, and the use of this test to investigate the effects of temperature and film thickness is reviewed.

second, the optimization of viscosity tests and their use to study premature curing of the ink in the fountain on the press is presented. The use of a nitrogen cover to retard unwanted curing is also examined with this test. Third, the development of the squeeze flow, poker-chip, and ultrasonic tests as ink cure monitoring tools is discussed. Finally, the examination of inks from the BEP quality control program is reviewed and a correlation between ink cure rate and performance is developed.
\end{abstract}




\section{INTRODUCTION}

At the request of the Bureau of Engraving and Printing (BEP), the National Bureau of $S$ tandards (NBS) is conducting a cooperative research program with BEF to investigate the mechanical properties of printing inks. The objectives in this program zre to develop a basic understanding of the influence of mechanical properties on performance and to use this understanding for the development of better quality control (QC) tests, optimized ink formulations, and improved printing procedures.

The previous work in this program (see last year's annual report, ref. 1) has established curing as an important factor in ink performance on the press. This is because the curing that oceurs on the press during printing changes the mechanical properties of the ink and good performance is obtained only if the appropriate rheological states are achieved at the proper points on the press. To study this probiem, test methods are being developed to measure the mechanical properties of ink samples both before and during the drying (curing) process. These tests are then used to examine selected ink samples, and the results are compared with spoilage data (percentage of printed sheets with unsatisfactory printing) for the inks obtained at BEP.

This report discusses the results obtained in the program during the past year. The discussion will be presented in six parts. First, the use of the rubber mill as an improved device to study ink curing under conditions that simulate to some degree those found on the press will be discussed. Second, the use of viscosity measurements to monitor curing will be reviewed and the results of tests on temperature, film thickness, and environmental effects will be discussed. Third, a new technique to follow curing via squeeze flow measurements will be introduced. Fourth the development of the poker-chip test for raeasuing ink properties will be summarized and a comparison between viscosity and poker-chip results will be given. Fifth, the new ultrasonic test device for ink mechanical properties measurement being constructed for BEF will be reviewed and proposed modifications and improvements to be made during the coming year will be outinged. Finaliy, results will be presented frorn tests on a series of eight inks whose performance was determined in the QC program conducted at BEP in early 1982.

It is worth noting that both the squeeze flow and the pokerchip tests have an important advantage. Simple versions of these tests can be performed either with commercial instruments or with slightly-modified, standard Iaboratory equipment. For example, the squeeze flow tests performed here utilized a simple and 
inexpersive hardness tester. The poker-chip experiments, on the other hand, were examined in more detail since it was of interest to determine the effect of stretching rate. To obtain a sufficiently large range of rates, specially modified equipment was reeded. Once the optimum testing rate is determined, however, a much simpler version of the equipment can be designed and utilized. ConsequentIy, both test methods offer the possibility for developing simple and inexpensive characterization methods. The only question is whether these tests can provide information that is useful for quality control purposes. This topic is addressed, at least in part, by this report. 


\section{SCUS SION}

RUBBER MILL CURING

Before Iast year the ink cure studies were conducted by placing ink samples on a two roll apparatus in which one role was heated and both rolls were rotating. The heated roll was maintained at $80 \mathrm{C}$ (approximate temperature of plate roller on the press). Thus the ink was subjected to high temperatures in a thin film for maximum exposure to oxygen. Moreover, since the rotation constantiy agitates and renews the outer surface, a hard outer crust does not form and limit exposure to oxygen. The ink to be tested was placed on the mill and at various cure times samples were extracted for characterization. In this way the changes in properties could be measured as the ink cured. Such experiments were conducted on a wide range of inks and this provides an extensive data base for comparison.

One question that has arisen in these studies, however, is that the cure rates obtained were relatively slow (more than 30 minutes) compared to the residence time on the press. As a result it is important to ask if these results are directiy pertinent to performance on the press. The comparison between the two situations, however, is not a simple one since there are important differences. For example, the film thickness on the test device was quite large compared to that on the press and it was proposed that this limits the exposure to orygen, thus reducing the cure rate. This hypothesis could not be tested, however, since the ilm thickness on the test device could not be varied in a controlled manner.

During the last yesi a new ink cure test procedure was devised. For these tests the inks were cured by placing samples on a rubber mill. This mill has important advantages since the film thickness could be varied over a wide range and the temperature of both rolis could be accurately controlled to provide a more uniform and realistic environment.

To examine the effects of temperature and film thickness, a series of tests was conducted on the rubber mill. The time required for the ink to solidify (i.e. become so rigid that a viscosity could not be measured) was determined at different temperatures and filr thicknesses. The results are Iisted in Table I. They indicate that the cure rate increases very rapidiy as the temperature ircreases and the film thickness decreases. Consequently, very rapid rates are obtained at high temperatures and low film thickresses. Moreover, it must be remembered that the ink or the press is preheated $3 \pi d$ held at 60 C in the fountain for some time before transfer to the rollers, while in the tests on the mill the ink is applied at room temperature. Finally, the numbers in Table I correspond to a cure state near the end of curing so important changes occur at much shorter 
times. Taken together these results indicate that the cure rates observed in the tests performed here are compatible with the assertion that significant curing occurs on the press during printing and that this is a major factor in ink performance.

Another important conclusion was obtained from these tests and other similar experiments, some of which will be discussed in the rest section of this report. The data suggest that there is a uniform trend in drying rate as the temperature and thickness are altered; i. e., there is no indication of a change in mechanism at temperatures below 80 C. Above 80 C this may not be true as indicated in the next section. As a result, it was assumed that comparisons of drying rates for different batches of the same ink formulation made at one set of conditions provides at least a qualitative indication of the relative rates at other conditions. For the majority of experiments performed here, the temperature was reduced to $40 \mathrm{C}$ and the film thickness increased to $0.3 \mathrm{~mm} 50$ that the cure rates were sufficiently slow to permit the changes in mechanical properties to be followed easily.

\section{VISCOSI TY MEASUREMENTS}

The work on viscosity measurements can be divided into three parts. The first concerns a series of tests that were performed on inks prepared with a new mixer at BEP. The results of these experiments have been summarized in a previous report (ref. 1 ) and will not be discussed here. The second topic concerns refinements that have been developed to simplify the characterization of viscosity before and during cure. The third topic involves the results obtained in cure tests which examine the dependence of curing rate on temperature and oxygen exposure. Both of these latter topics will be discussed below.

While measuring the viscosity of some inks obtained during the QC program at BEP, an unusual effect was observed. For some inks it was found that at the beginning of the test there was a large decrease in viscosity as a function of time for measurements made at constant shear rates. The time scales involved were much longer and the changes observed were much larger than those associated with the yield behavior that has been discussed in previous reports (1). Moreover, whereas the yield behavior was reproducible and recoverable if the ink was al lowed to rest, these new changes were not reproducible and were not recoverabie regardless of how long the inks were allowed to rest in the test machine.

After much study the following explanation has been developed. When the cone and plate of the viscometer are moved together at the beginning of the test, the ink is placed under a high compressive load. Under normal conditions the ink would flow in the radial direction to relieve this load. With some of the inks tested recently, however, this flow was apparentiy restricted and thus the reduction in these normal (i.e. perpendicular to the shear flow) loads was 5 low. particularly true when the cone angle was small.

This was

The experiments 
show that the apparent viscosity measured by the usual rotary motion was much higher when these stresses were present than it was under normal conditions. The presence of the rotary motion during the measurement, however, seemed to generate or facilitate a secondary flow in the radial direction. This radial flow reduced the normal loads with the result that the viscosity measured with the rotary motion also gradualiy decreased. This leads to an explanation that the flow used to measure the viscosity also facilitates a secondary flow that sIowIy reduces the apparent viscosity by relieving the normal loads. So long as this effect is present, stable values for viscosity cannot be ob $\mathrm{ta}$ i $\mathrm{ned}$.

To study this effect, the apparatus was adapted to measure normal forces as well as viscosity. To keep these normal forces from becoming too large, a 1 degree cone was substituted for the 0.5 degree cone utilized in the previous experiments. The results of tests with this apparatus indicate that steady rotary shear maintained for a short time will reduce the normal loads to a level that depends on the magnitude of the shear rate, high shear rates giving lower residual normal loads. To obtain stable values for viscosity, therefore, it is necessary to subject the ink to a shear rate high enough to eliminate the normal loads. The experiments indicate that this can be accomplished by testing the sample in both rotary directions for a few seconds at a shear rate of $305^{-1}$. After this pretreatment, stable and reproducible values can be obtained for viscosity at shear rates up to several hundred reciprocal seconds. Consequentiy, this procedure is now used for all of the ink tests being performed.

Even without the complications discussed above, however, the determination of viscosity over a wide range of shear rates is a time consuming process. Although such a characterization is necessary in some cases, the results obtained in this program suggest that a simple measurement made at an intermediate shear Iate (between 1 and $1005^{-1}$ ) can often be useful when a minimum amount of time is available to obtain information. This is il lustrated in Figures 1 and 2. Figure 1 shows the viscosity as a function of shear rate for a rumber of different inks. A close examination of this Figure shows that a comparison of different ink formulations or samples of the same formulation fabricated several years apart requires a complete characterization since both the level and shape of the curves can be different. For the day-to-day variations in 5 amples with the same formulation, however, the differences are primarily vertical shifts of the curve. Consequentiy, useful information can be obtained by a measurement at a single shear iate. Since the curves come together at high and Iow shear rates, the measurement should be made at an intermediate value. A similar conclusion can be made for cure monitoring data (Figure 2) since the major change during curing is a roughly equal elevation in viscosity at al but the highest shear rates. Based on these observations, the subsequent work in this program utilized viscosity measured at an intermediate shear rate for both QC and cure monitoring experiments. It is a Iso suggested that the present BEP viscosity 
test should be modified. At present this test is used to determine a yield stress and a high shear rate viscosity. The results of the tests performed here suggest that more useful information would be obtained if the maximum shear rate were reduced to the range between 1 and $100 \mathrm{~s}^{-1}$.

The third area of research involving viscosity measurements concerns the study of a number of ink batches for which 5 amples were available both from the ink fountain on the press and from reference 5 amples that were taken when the ink was formulated and stored in a freezer at NBS. An examination of these inks made it possible to determine what effects exposure to high temperature and oxygen in the fountain had on the inks'properties. The fountain samples were usually available because the printers were either very happy or very unhappy with the ink and saved some for evaluation. Since being removed from the fountain, these samples have been stored in the freezer (-12 C) at NBS with the reference samples. A comparison of fountain and reference samples

indicated that there was a wide range of differences in inks. In some cases the reference and fountain samples were identical, in other cases the fountain ink had a much higher viscosity than the corresponding reference ink indicating that some curing had alieady occurred, and in 5 till other instances the uncured fountain and reference inks behaved in a similar manner but their curing behaviors were quite different in that the fountain ink reached a fuldy cured state much more rapidiy. Figure 3 , for instance, shows an example of this thicd case for a sample of ink batch 2 prepared on $1 / 26 / 82$. The tests were performed at a shear Iate of $305^{-1}$. This Figure clearly indicates that the fountan ink exhibited a much shorter induction period and perhaps a somewhat faster cure rate. As might be expected based on such results, the spoilage figures for this ink were quite high:

13. $9 \%$. Variations of this type can obviously affect performance and probably arise from variations in ink history. For example, a wide range of temperatures has been noted in measurements made in the fountains on various presses at different times.

A number of curing experiments were performed with a nitrogen enviconment placed around the mill to see if the premature advancing of the cure could be retarded by exclusion of oxygen. It was found that this did not stop the curing but could delay it and/or slow it down. Figure 4, for example, shows the same data as Figure 3 but with an added curve for curing of the reference ink sample under a nitrogen atmosphere. Similar Iesults were obtained with the fountain sample and with other inks. It is clear from these data that the nitrogen substantially increases the induction period and may somewhat reduces the initial rate of viscosity increase. of course, once curing is weIl under way the nitrogen might not be expected to have much of an effect if it actsonly as an initiator.

There are two possible explanations for the continution of the curing reactions under the nitrogen environment. First, there may be a thermally initiated cure which would be independent of atmosphere. Second, since the inks were not 
prepared and stored under nitrogen, some oxygen may be dissolved in the ink, and this may act as an initiator. Nevertheless, the results suggest that a nitrogen environment over the ink fountain on the press might be beneficial in providing some retardation in the premature cure of the ink on the press.

In considering the use of nitrogen, however, an additional result from these tests must also be considered. The data obtained here indicated that the effects of $\pi i t r o g e n$ were temperature dependent. If the cure rate is characterized by measuring the time required for the ink's viscosity to exceed 20 $x 10^{6} \mathrm{mPa} s$, then this parameter can be determined for various cure experiments on a given ink sample and plotted against mil cure temperature. Figure 5 shows data of this type for the same ink as in Figure 4 cured in both an air and a nitrogen environment. Based on this result, it can be concluded that the effects of nitrogen decrease as the temperature increases and at temperatures over $80 \mathrm{C}$ the environment has little effect on curing. Perhaps in this range thermal initiation is the dominant mechanism. In any case it is clear that if a nitrogencover is used over the ink fountain or the press, it may not be effective uniess there is some control over the fourtain temperature.

Another way to plot the data in Figure 5 is to use a Iog cure time vs reciprocal temperature coordinate system, i.e. an Arrhenius type plot. If this is done, the data can be roughIy fit to straight Iines, Figure 6. To the extent that this pIot has any fundamental significance, the results would suggest an activation energy of about 12 keal/mole in air and just 5 ightly higher in nitrogen (see Figure 5)

\section{SIUEEEZE ELLW IE $\underline{\text { STS }}$}

The measurement of viscosity with the convertional cone and plate viscometer is time consuming even when only one shear rate is measured and so alternative methods to follow cure are being studied. One possibility is squeeze flow. In this test a measured amount of ink is placed between two sheets of ceIIophane and this 5 andwich is inserted between the two plates in a hardness tester. The hardness tester applies a weight to one plate and measures the plate separation. The weight causes a squeeze flow of the ink and this al Iows a decrease in the pIate separation. Initialiy this decrease in thickness is iapid but it soon sIows dramaticaliy and thus thickness values taken after one minute are quite reproducibie. This one minute value is related in an as yet undetermined way to the ink's low shear rate viscosity and yield behavior. As the ink cure time on the mill increases, the Iimiting separation increases and thus the test provides a very quick and easy way to follow the curing process.

Experiments are now underway to examine this test as a simpler and faster (but probably less informative) aIternative to viscosity measurements. One evaluation procedure that has been employed is to use this technique to examine curing of the inks generated in the QC program at BEP. The results of these tests 
will be discussed Iater in this report. In addition, experiments are now underway to compare squeeze flow measurements with the rormal viscosity tests. Finally, the various analyses that have been conducted and published on squeeze flow will be studied to see if anything can be learned with regard to what this test measures-in rheological terms.

\section{POKER -}

Although the viscosity and squeeze flow experiments help characterize the inks, they may not measure all of the properties that are important in ink performance. For example, the film splitting behavior of the inks may not be adequately characterized by these tests. In an effort to provide some information on such "tack like" properties, the poker-chip test from rubber technology is being considered as a possible ink test. The version now under development involves two plastic cylinders ( 10 mass for low inertia), one attached to the crosshead on a tensile test machine and the other attached by a strong cord to the load cell. An ink sample is sandwiched between the cylinders and pulled to failure in tension. The failure is in the ink and involves cavitation and elongational flow. The sIight elastic extension of the cord helps develop a smooth loading of the ink during the experiment.

In terms of ink performance it is usually the high strain Iate behavior that is of most importance; however, the strain rate dependence may also be of interest. In order to obtain the

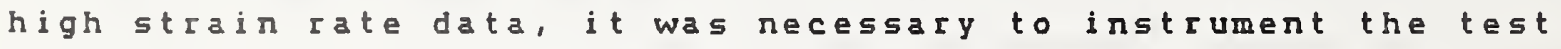
machine for rapid data acquisition. Moreover, for the determination of the rate dependence, an automated test facility is convenient since very slow as well as very fast tests must be performed. These requirements have been met during the past year by developing the necessary hardware and software to computerize the test machine.

The results of a typical experiment are shown in figure 7 which gives the load/time curve for an ink sample pulled at a cross-head speed of $100 \mathrm{~cm} / \mathrm{min}$. Experiments such as that i I Istrated in this Figure were conducted at a series of crosshead speeds to determine the loading rate dependence of the load at failure, $P$. When data from these tests areplotted, results such as thosecshown in Figure 8 are obtained. These data show a strong dependerce of $P_{c}$ or cross-head speed.

Experiments of this kind were also conducted using partially cured ink samples obtained from curing experiments on the rubber mill. Eigure? shows the results of such tests on ink batch? fabricated on $1 / 16 / 82$. The results are in some respects similar to those seen in the corresponding viscosity tests. The major change produced by curing is a roughly vertical displacement of the curves. Only at the very highest cross-head speeds is there a tendercy for the curves to come together. As a result it is of interest to ask how the data in Figure 9 compare with data for similar experiments on the same ink using viscosity measurements 
to follow cure. Such comparison experiments were performed and the results are shown in Figure 10. The vertical scale in this Figure represents failure load in kg for the poker-chip test and the viscosity in mPa's divided by $10^{6}$ for the cone and plate tests. In both cases the rates were chosen to give the maximum sensitivity to cure and the rinimum sensitivity to rate, i.e. a cross-head speed of $0.05 \mathrm{~cm} / \mathrm{min}$ in the poker-chip test and a shear rate of $5 s^{-1}$ in the cone and pIate experiments. The comparison made in this Figure suggests that both experiments give qualitatively similar results on cure. The poker-chip test may be more sensitive to the first phases of curing the experimental scatter is larger. In the Iatter phases of curing viscosity measurements are much more sensitive. Further work is now underway to esamine these trends in more detail and to determine if it is necessary to perform both tests to characterize curing behavior or if one test is sufficient.

\section{ULTRASON IC TEST}

The research conducted prior to this year concluded that NBS's uItrasonic, thin film test device would be very useful in ink characterization. A complete discussion of this measurement technique is contained in the appendia to this report. Based on this conclusion, NBS undertook the development of a second such system to be constructed for BEp. This appartus has now been designed, assembIed, and tested. It has been modified relative to the NBS system in several important ways. First, the system is designed to be more automated. Second, rather than using the strip deIay I ine (see appendix) as the measurement substrate, a normal incidence technique was used. In this method, a shear wave transducer is mounted on one end of a quartzcyIinder 2.54 $\mathrm{cm}$ in diameter and $7.62 \mathrm{~cm}$ Iong. A shear wave pulse is transmitted down the center of the rod and reflects back from the other end. The sample is applied as a coating to that end of the rod and the reflection coefficient at the quartz/sample interface is determined experimentally. The reflection coefficient is a measure of the attenuation and phase shift of the wave during the reflection. The shear mechanical properties of the coating can then be calculated from this coefficient. Since the objective here is simply tomonitor curing rather than to calculate the absolute values of the mechanical properties, hovever, it is generaliy adequate to measure only the atteruation of the signal and follow changes in attenuation as the coating dies.

The electronics of the new system involves two parts: a pulse generator/receiver and an automatic attenuation measurement unit. The pulse generator/receiver generates a short burst of sinusoidaliy varying voltage (main pulse) which when applied to the transducer is converted to mechanical motion in thiscase an uItasonic shear wave). This pulse of mechanical motion travels down the quartz rod and is reflected back and forth until it gradualiy dies out from the natural Iosses in the quatz, the loss at each end reflection, etc. Each time the puIse reflects from the end of the rod with the transducer, it generates an electrical signaI in the transducer that can be used tomonitor 
the wave in the rod. This signal is returned to the pulser for amplification. The output is a series of signals (echoes) with decreasing amplitude. This echo pattern can then be viewed and analyzed on an oscilloscope or the automatic attenution measurement unit (AMU)

The second part of the electronics on the new system is the AAMU. This unit has two variable gates that can be set to select two echoes, for example, the first and second. The electronics then measures the relative heights of the two selected echoes and outputs this in terms of an attenuation either on a meter or as a DC voltage that can be monitored on a chart recorder.

The new system for BEP has been assembled and tested. The results of these experiments suggest several modifications that would improve the usefulness of the instrument. In addition to adding an oscilloscope and recorder to the system, a temperature chamber is needed so that the drying rates can be varied and the temperature dependence can be studied. More effective methods for mounting the quactz rod are also required so that the sample can be easily applied and removed. Finally, a better method is needed to apply thin films of uniform and controlied thickness. All of these areas will be addressed in the coming year.

\section{TESTS ON THE QUALITY CONTROL INKS}

During the ink QC program at BEP in early 1982 , a series of inks were generated and their performance on the press was characterized by determining spoilage figures (the percentage of printed sheets with unsatisfactory printing). Samples of these inks were obtained during manufacture and stored in a freezer for later evaluation. Based on the spoilage figures, eight inks were selected for detailed study: four inks with very low spoilage and four with very high spoilage (Table II). These inks were examined by measuring the viscosity as a function of shear rate and curing behavior using the rubber mill and squeeze flow experiments. In addition, these same inks were studied by BEP using a number of tests. The BEP experiments found only one difference among the inks that correlated with spoilage. One of the tests that was performed involved studying the cure rates of the inks by drying them and measuring the changes in absorbance at $720 \mathrm{~cm}^{-1}$. The drying 5 ates for the eight inks separated into two distinct groups. Within each group the curing rates varied by less than $\pm 8 \%$ while on average the inks in one group cured at a $35 \%$ slower 5 ate than those in the other group. All of the inks with low spoilage fell into the group with the slower drying $5 a t e$ while all but one of the high spoilage inks exhibited Iapid cure rates. This corcelation is remarkable in light of all the uncontrolled variables in these tests, i.e. different presses, printers, fountain temperatures, etc. Moreover, the results support one of the major conclusions of the previous NBS annual report (1) from this program. This conclusion asserted that curing rate is a major factor in ink performance.

The tests performed at NBS on these inks gave quite similar 
results. The viscosity measurements on the uncured inks exhibited significant differences from sample to sample (the range of this variation is indicated in Figure 1). Despite this variation, however, noclear correlation could be established between these differences and the ink's performance on the press. It is interesting to note that in allof these tests the viscosities were significantly lower than those measured two years ago and used as our baselinedata for BK-62 Mod. 3 (see Figure 1). Moreover, as shown in Figure 1, the baseline curve for this ink has a shoulder between shear rates of 10 and 100 s-1 (less pronounced than that for BK-62). The ink samples tested recently, however, do not show this shoulder.

The I ower viscosities for the new inks were not unexpected since tests at BEP have shown a gradual decline in viscosity over the Iast few years in the high shear rate viscosities for these snks. The change in the shear rate dependence, however, was a surprise and indicates that there are major changes in the inks that occur gradualiy over the years. These changes may be due to differences in the raw materials. Whatever the cause, the printers seem to have had good success in adjusting to these gradual changes in the ink. Nevertheless, it seems clear that a detailed evaluations of the ink's properties should be performed periodicaliy to insure that a record of these changes is kept for future reference.

The drying rates of the eight selected inks were also measured at NBS using the rubber mill and squeeze flow tests. Figure 11 shows the results of these tests with the solid 1 ines representing inks with low spoilage and the dotted ines for inks with high spoilage. In the squeeze flow experiments the inks did not separate into two distinct groups based on curing rate as they did in the BEP tests. Instead the cure rates covered a wide range of values. Nevertheless, just as in the BEP tests the inks that cured slowly exhibited low spoilage while those that cured rapidly showed high spoilage. Moreover, the ore ink that was out of order in the BEP tests (high spoilage and $5 I$ ow curing) was a 150 out of order in the NBS experiments (designated A in Eigure 11). Thus there was a clear correlation between cure rate and performance.

Another comparison can be made by characterizing the cure rates in a different way, i.e. the time required for the hardness test to reach the value of 30 . These values are Iisted in Table I for the eight inks. The general conclusion that these results and the results of other similar tests suggest is as follows. For slow cure rates (cure times) 37 min) good performance is obtained. For rapid cure rates (cure times ( 33 min) poor results are typical. For intermediate cure rates the performance vary over a wide range. One factor influencing this variation in behavior is that the ink performance is known to depend on other factors such as the setup of the press.

One of the most significant observations in these tests was that the inks exhibited a wide range of cure rates. In theory 
a 11 of the inks were prepared from identical ingredients using exactly the same procedures.

Despite this, however, the cure

times as measured in Table II varied by almost a factor of two.

This should not be the case and clearly indicates that the

variations generated during the fabrication procedure were much

too Iarge. The use of a QC test that measures cure rate could

reduce this uncertainty if the inks with unsatisfactory cure

rates were discarded. Experience suggests however that BEP is

reluctant to discard inks and 50 an alternative is needed. The

answer may lie in conducting a study of the ink fabrication

procedure. The objective would be to identify those factors that

contribute to the variability of ink cure and to search for ways

to minimize their effects. 


\section{CONCLUS IONS}

This report summaizes the results obtained during FY-83 in the NBS program on ink behavior and performance. The report covers six specific research areas. The first is the use of a rubber mil as an improved ink curing device. This procedure simulates some of the conditions found on the press and therefore helps make the results more meaningful. Tests with the mill have examined the accelerating effects of increasing the temperature and decreasing the film thickness on the cure rate. The results showed that very high cure rates could be obtained on the rollers of the press. In addition, the data suggested that the dominant cure mechanism remained the same over a wide range of conditions.

The second area of research involves viscosity measurements. It was concluded that a complete shear rate characterization is desirable when comparing different inks or the same ink tested several years apart. For quality control and cure monitoring, however, the measurement of viscosity at an intermediate shear rate was found to be a useful characterization tool. It was suggested that a modification of the present BEP procedure along these Iines would be advisable. The application of viscosity tests to ink samples obtained from BEP indicated that premature curing can occur in the ink fountain on the press. This can almost certainly affect performance. The use of a nitrogen cover over the rubber mill demonstrated that curing on the ink could be retarded at temperatures below 80 C. This suggests that the use of a nitrogen cover over the ink fountain on the press might help reduce the premature curing that can occur there.

The third area covered in this report involves squeeze flow experiments. This is a new and promising technique to follow curing with a very simple test. It was shown to be quite useful in experiments with the BEP quality control inks.

The fourth area of research is the poker-chip test. An examination of this test demonstrated that it was useful for characterizing an ink both before and during curing. A comparison between the viscosity and poker-chip tests showed a number of similarities. Both exhibited a strong rate dependence and both showed dramatic changes as the ink cures. The pokerchip test was more sensitive to the early phases of curing while the viscosity test provided a better picture in the latter phases.

The fifth area covered in the report is ultrasonic testing. The new apparatus being developed for BEP was reviewed and suggestions for improving the device were proposed. These suggestions included a more complete electronics package and a temperature control chamber to adjust curing rate. 
The tinal area covered in the report is the evaluation of the inks generated during the quality control program at BEP. A clear correlation was found between curing rate and spoilage figures. Inks with slow curing rates gave very low spoilage while inks with high curing rates gave high spoilage. For those inks with intermediate cure rates, some had high spoilage and some had Iow spoilage. This suggests that other factors, such as the setup of the press are involved in determining performance in this range. These results also indicate that the variability in these presumably identical inks was very large.

This is almost certainly an important source of ink spoilage and should be addressed. Although inks with unsatisfactory cure rates can be identified and discarded, a better approach would be to determine those factors that cause the variations and minimize or eliminate them. 


\section{REE EE RENCEE}

1. Donald L. Hunston, "Relationships Between Mechanical

Properties and Performance of Inks as a Basis for Quality Control Techniques," NBSIR 83-2691, May 1983. 
TABLE I: CURING OF INKS ON RUBBER MILL

\begin{tabular}{ccc} 
TEMPERATURE & EILM THICKNESS \\
(C) & $\begin{array}{c}\text { TIME TO } \\
\text { SOLIDIFICATION } \\
(\mathrm{mI})\end{array}$ \\
\hline 40 & 0.3 & \\
50 & 0.3 & 65 \\
60 & 0.3 & 31 \\
60 & 0.1 & 21 \\
70 & 0.3 & 9 \\
70 & 0.1 & 12 \\
80 & 0.3 & 5 \\
\hline
\end{tabular}


TABLE II: COMPARISON OF INK CURE RESULTS

\begin{tabular}{|c|c|c|c|c|c|}
\hline $\begin{array}{l}\text { INK } \\
\text { BATCH }\end{array}$ & DATE & DES I GNAT I ON & $\begin{array}{l}\text { SPOILAGE } \\
(\%)\end{array}$ & $\begin{array}{l}\text { TIME TO } 30 \\
\text { HARDNESS } \\
(m i n)\end{array}$ & $\begin{array}{c}\text { BEP } \\
\text { CURE RATE }\end{array}$ \\
\hline 9 & $1-16-82$ & A & 22.8 & 37 & $S=S L$ OW \\
\hline 10 & $1-22-82$ & B & 11.2 & 31 & $\mathbf{E}=\mathbf{F A S T}$ \\
\hline 3 & $1-26-82$ & C & 9.9 & 29 & E \\
\hline 17 & $1-28-82$ & $D$ & 13.5 & 27 & $\mathbf{F}$ \\
\hline 7 & $1-12-82$ & $E$ & 0.74 & 33 & $\mathbf{s}$ \\
\hline 5 & $1-25-82$ & $\mathbf{F}$ & 1.64 & 42 & $\mathbf{s}$ \\
\hline 13 & $1-27-82$ & G & 1. 19 & 41 & $\mathbf{s}$ \\
\hline 9 & $2-2-82$ & H & 0.95 & 52 & $\mathbf{s}$ \\
\hline
\end{tabular}




\section{FIGURE CAPTIONS}

FIGURE 1: Baseline data for: BK-60=+, BK-62= $\triangle$, and BK-62 Mod $3=\square$. Range of data for recently tested sampIes of $B K-62$ Mod $3=0$.

FIGURE 2: Steady flow viscosity vs shear rate data for samples of BK-60 cured for 0 min. $(x), 10 \mathrm{~min} .(\nabla), 20 \mathrm{~min}$. $(\square)$, and $30 \mathrm{~min} .(+)$.

EIGURE 3 : Viscosity vs cure time for fountain ( $\diamond$ ) and reference ( $\Delta$ and $\square$ ) samples of ink batch 2 prepared on 1-26-82 cured on rubber mill at 40 C and a gap setting of 0.3 $\mathrm{mm}$.

FIGURE 4: Data from Figure 3 pIus a curve for a reference sample of the same ink cured on the mill under a nitrogen environment, +.

EIGURE $\underline{5}:$ Time to cure vs cure temperature for reference samples of ink \#2, 1-26-82 cured on the mill under an air environment, $\square$, and a nitrogen environment, $\Delta$.

FIGURE 6: An Arihenius type plot of the data in Figure 5 .

EIGURE 2: Load-time curve for a poker-chip test. Resolution is 143 points per second.

EIGURE : $:$ Failure load vs separation rate (cross-head speed) in the poker-chip tests on a sample of ink batch 9, 1-1682 .

EIGURE 9: Poker-chip test results for ink batch $9,1-16-82$ at various cure times on the mill: $0 \mathrm{~min}=>, 7 \mathrm{~min}=$ , $15 \mathrm{~min}=+, 25 \mathrm{~min}=\Delta, 32 \mathrm{~min}=\mathrm{x}, 37 \mathrm{~min}$. $=0$. and $43 \mathrm{~min}=\square$.

EICURE 10: Comparison of poker-chip $(\square)$ and viscosity ( $\Delta$ ) data on ink curing.

FICURE 11: Squeeze flow test results for the curing of the eight QC inks. Designations defined in Table II. 
Figure I

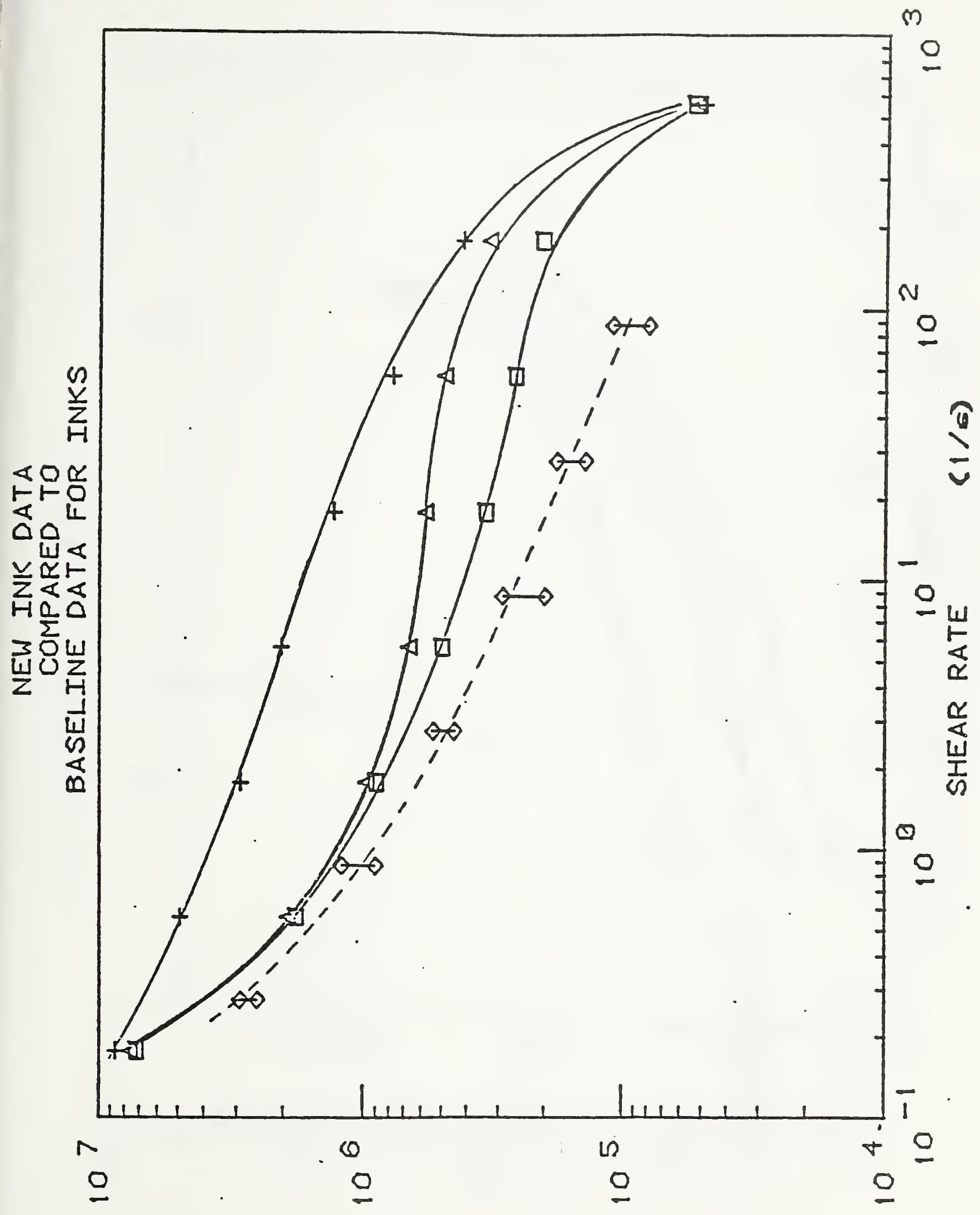

(s.o dw)

ALISOJSIA 
Figure 2

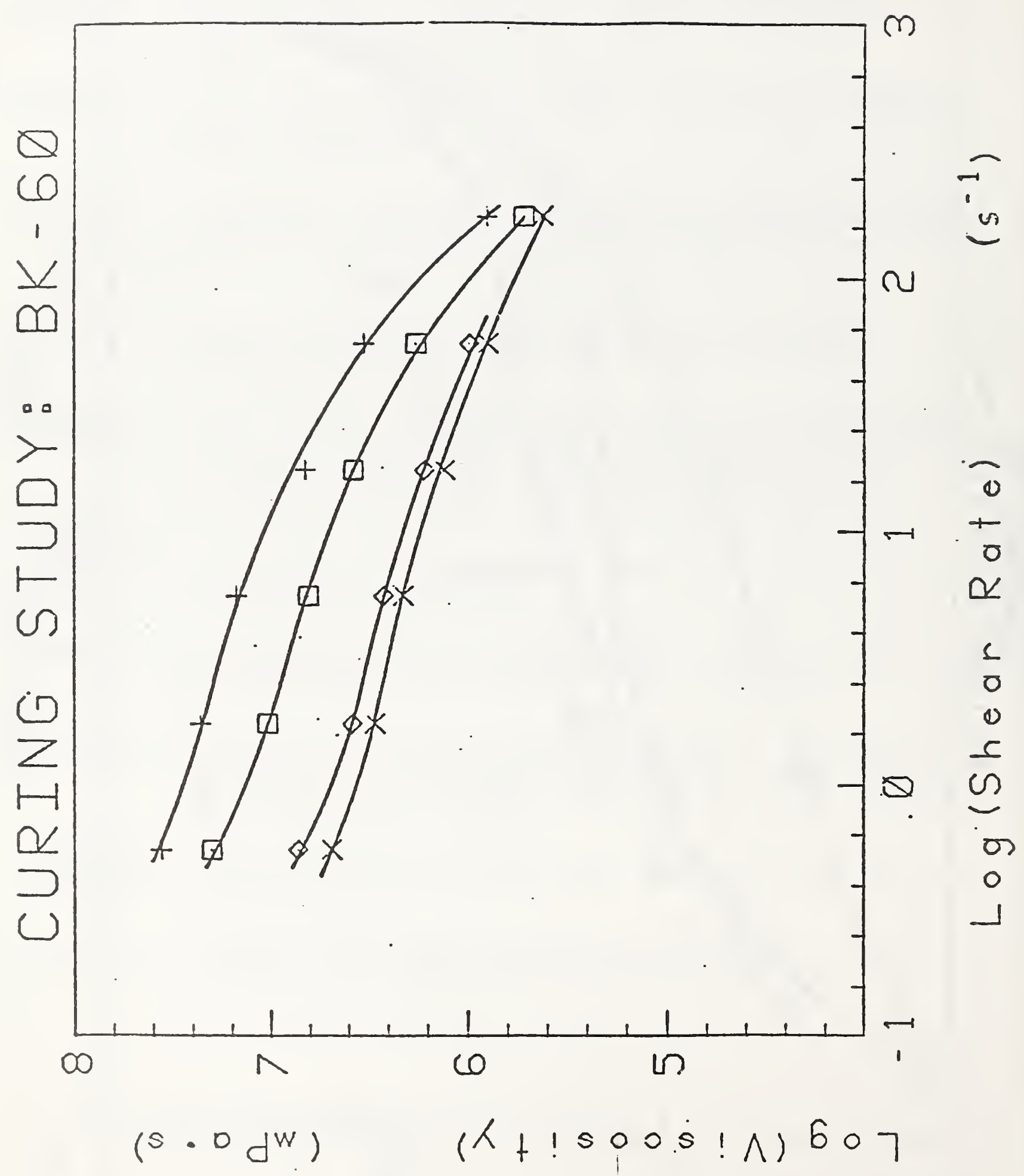


Figure 3

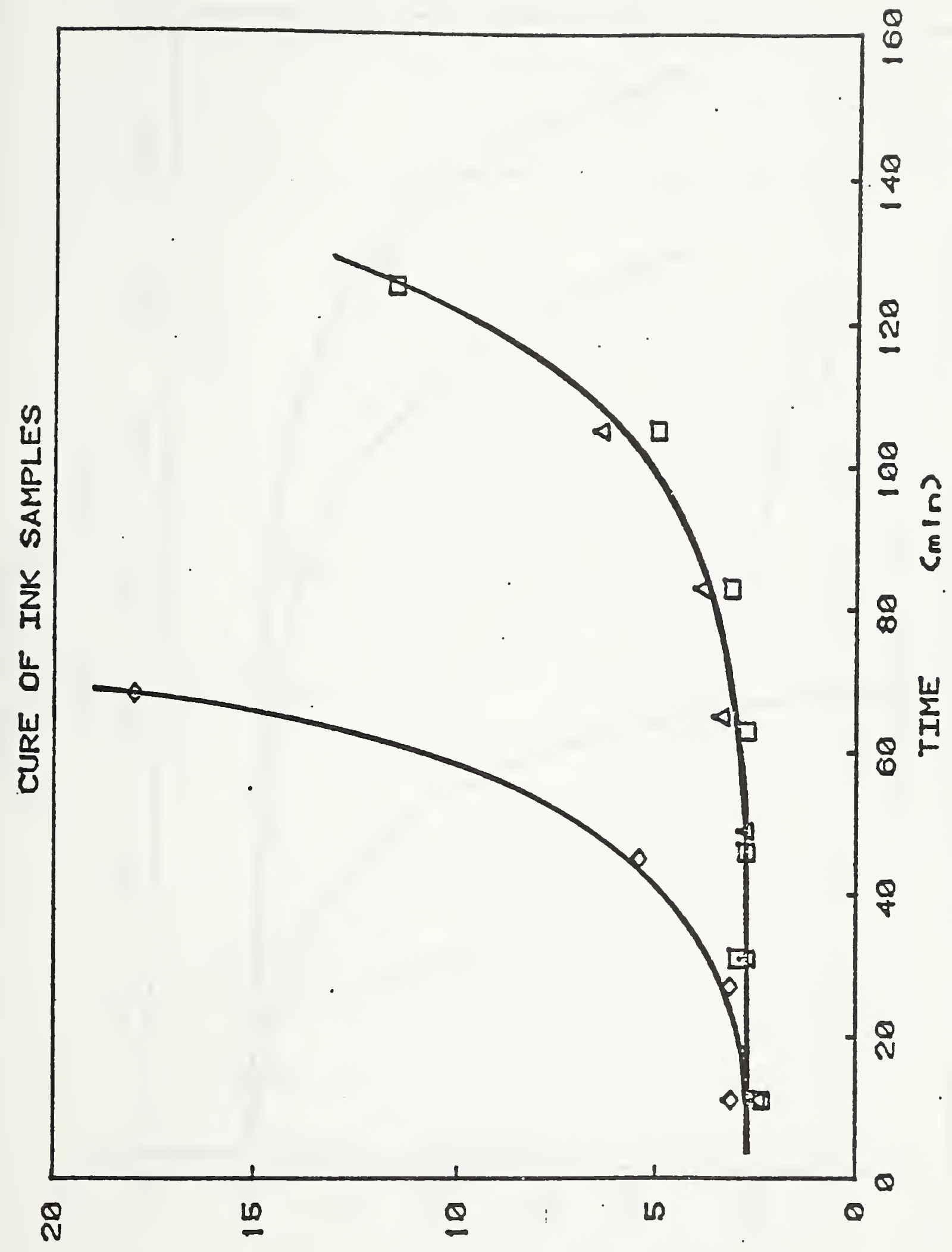

(3.0 dU) S-VOI X NIISOJSIN 
Figure 4

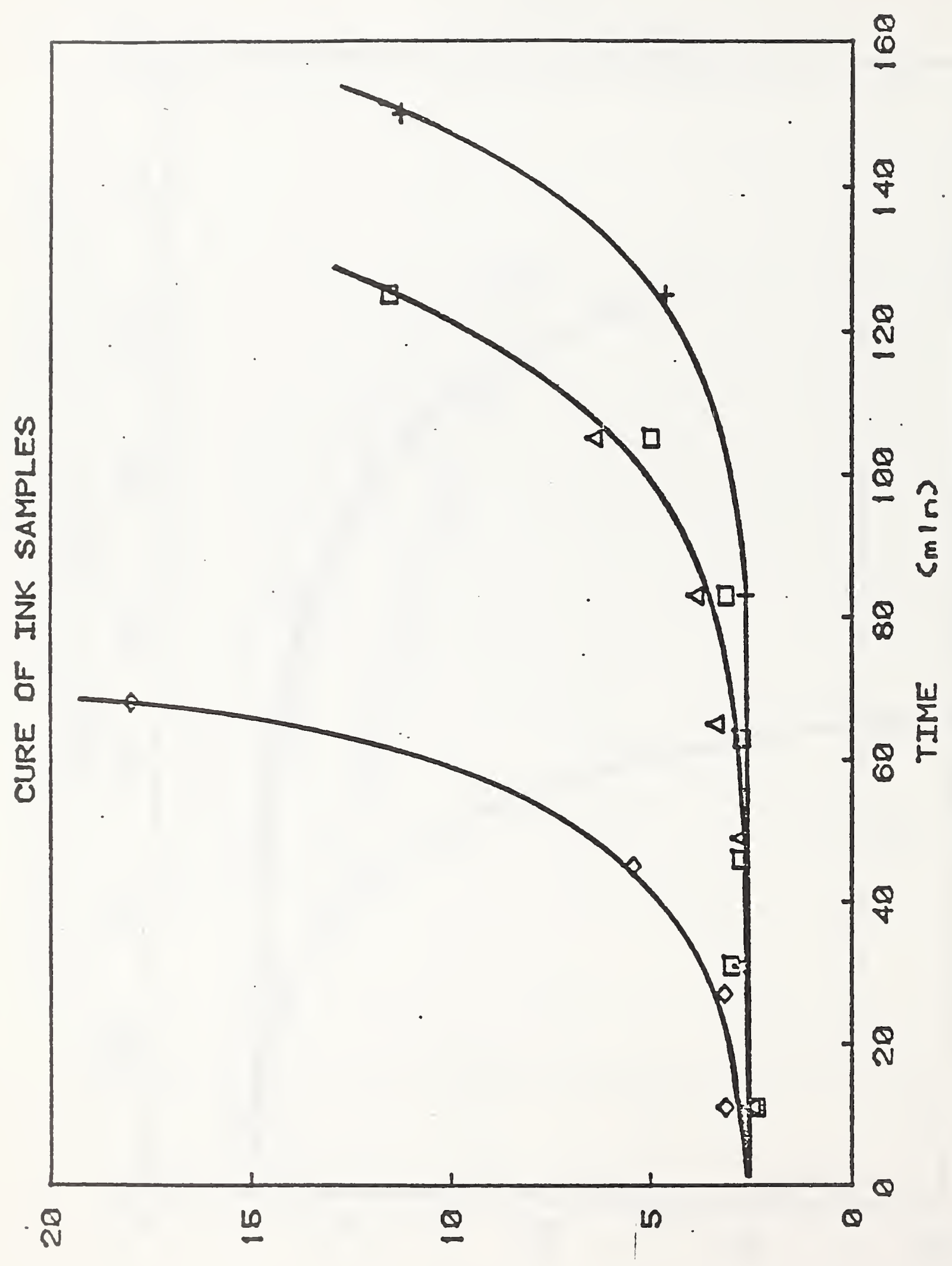


Figure 5

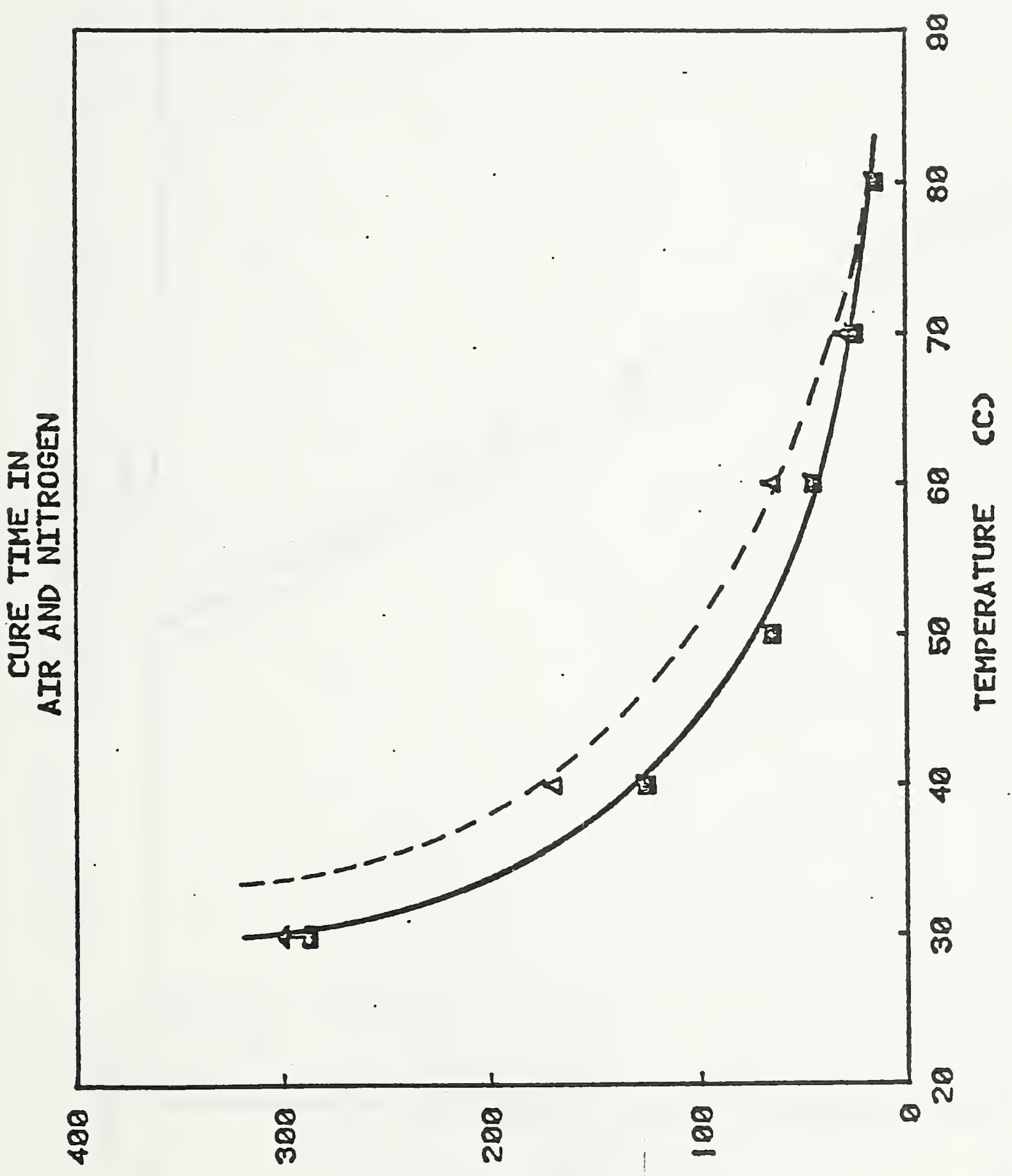

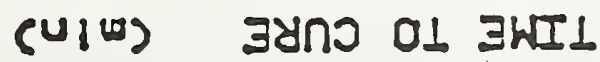


Figure 6

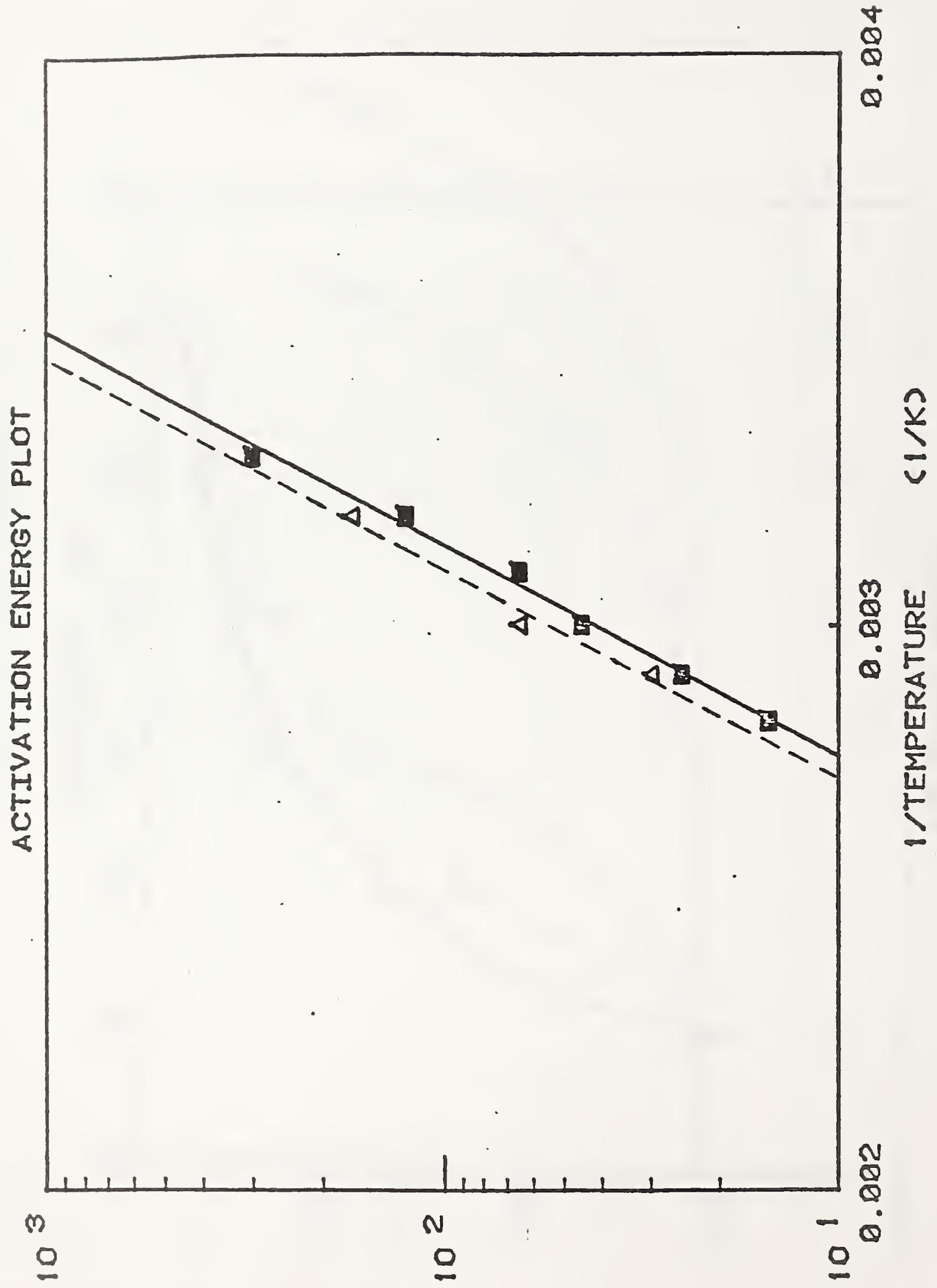

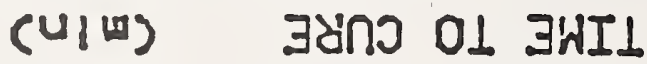


Figure 7

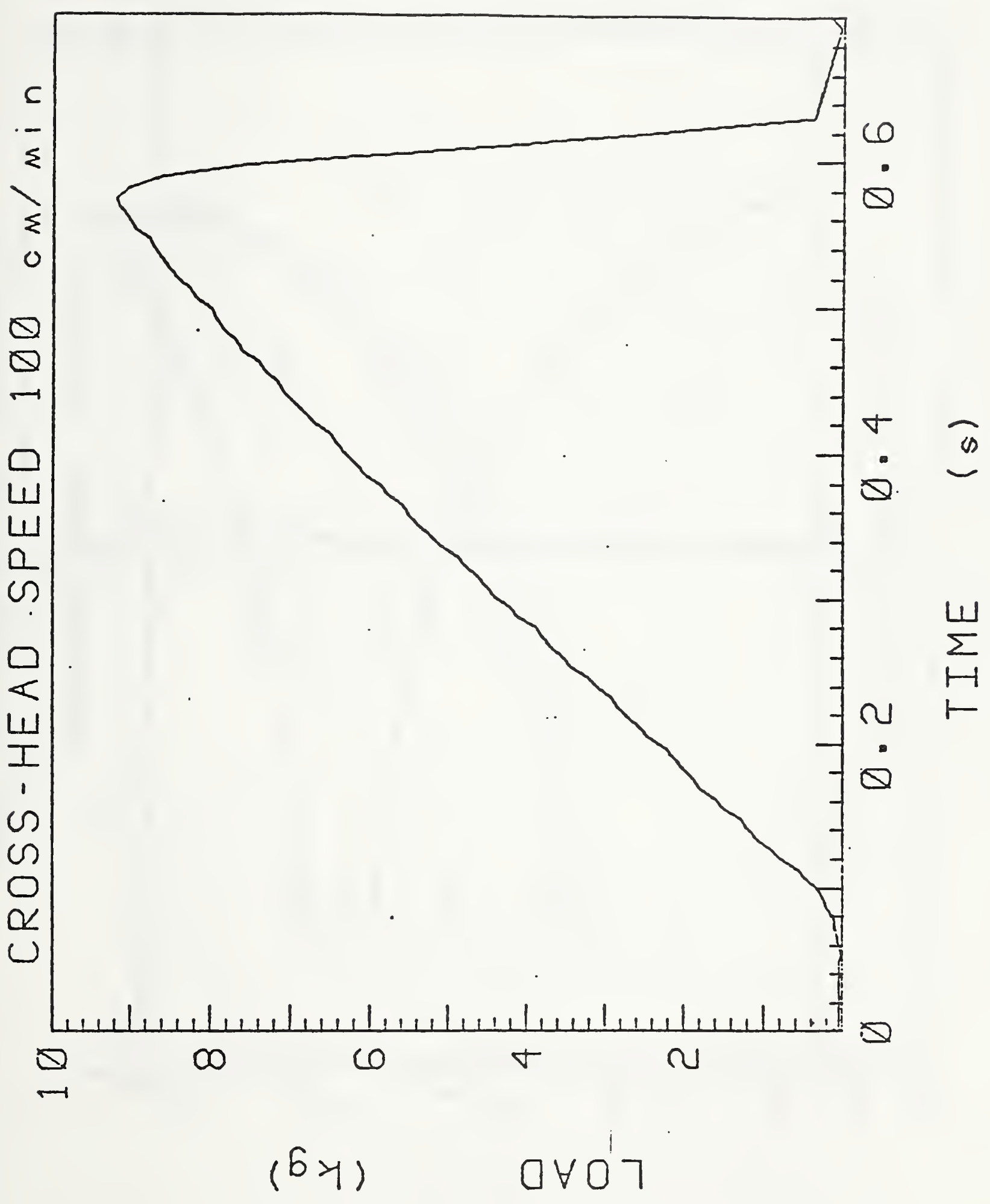


Figure 8

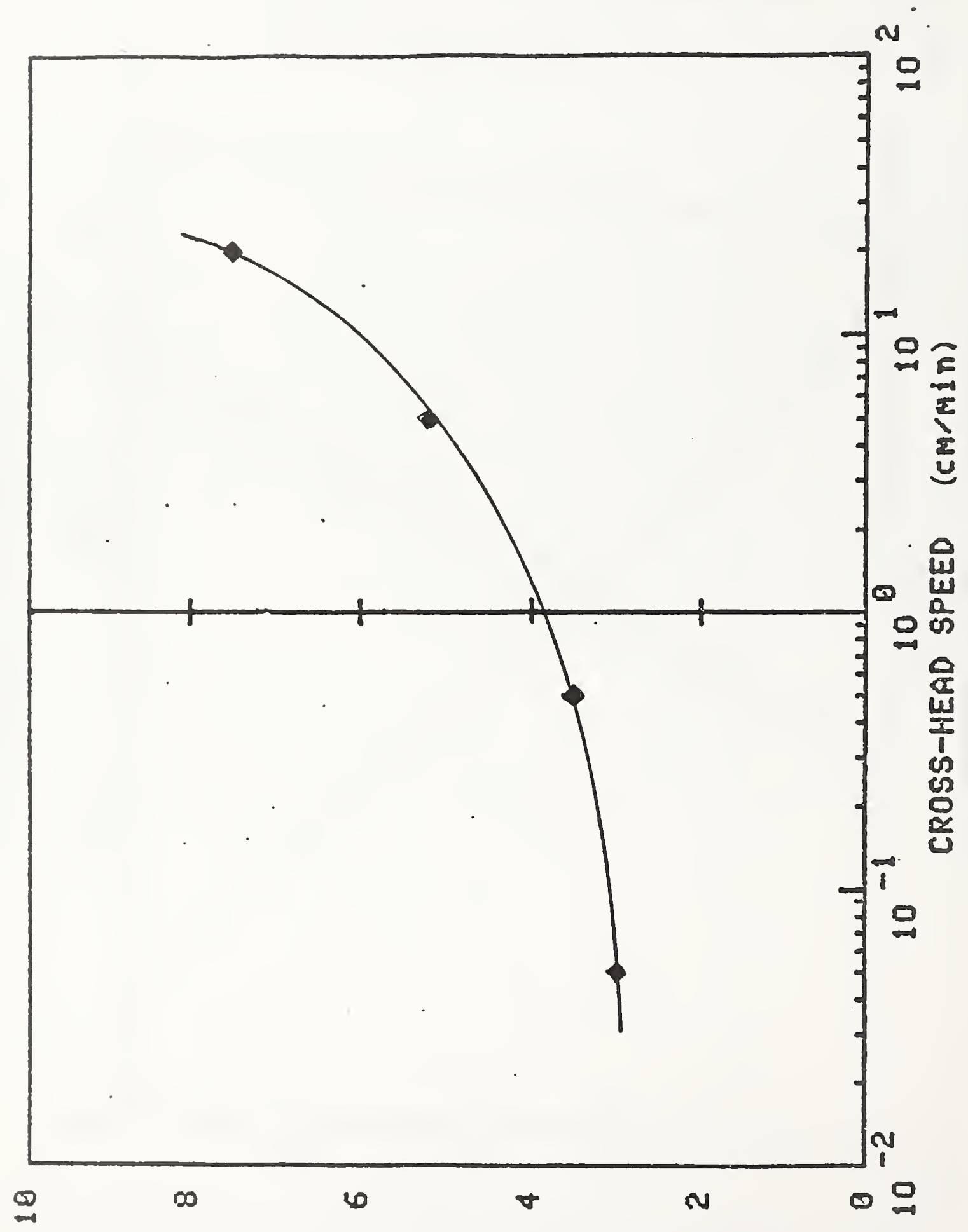

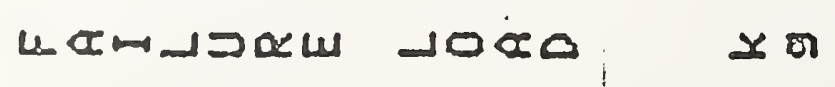


Figure 9

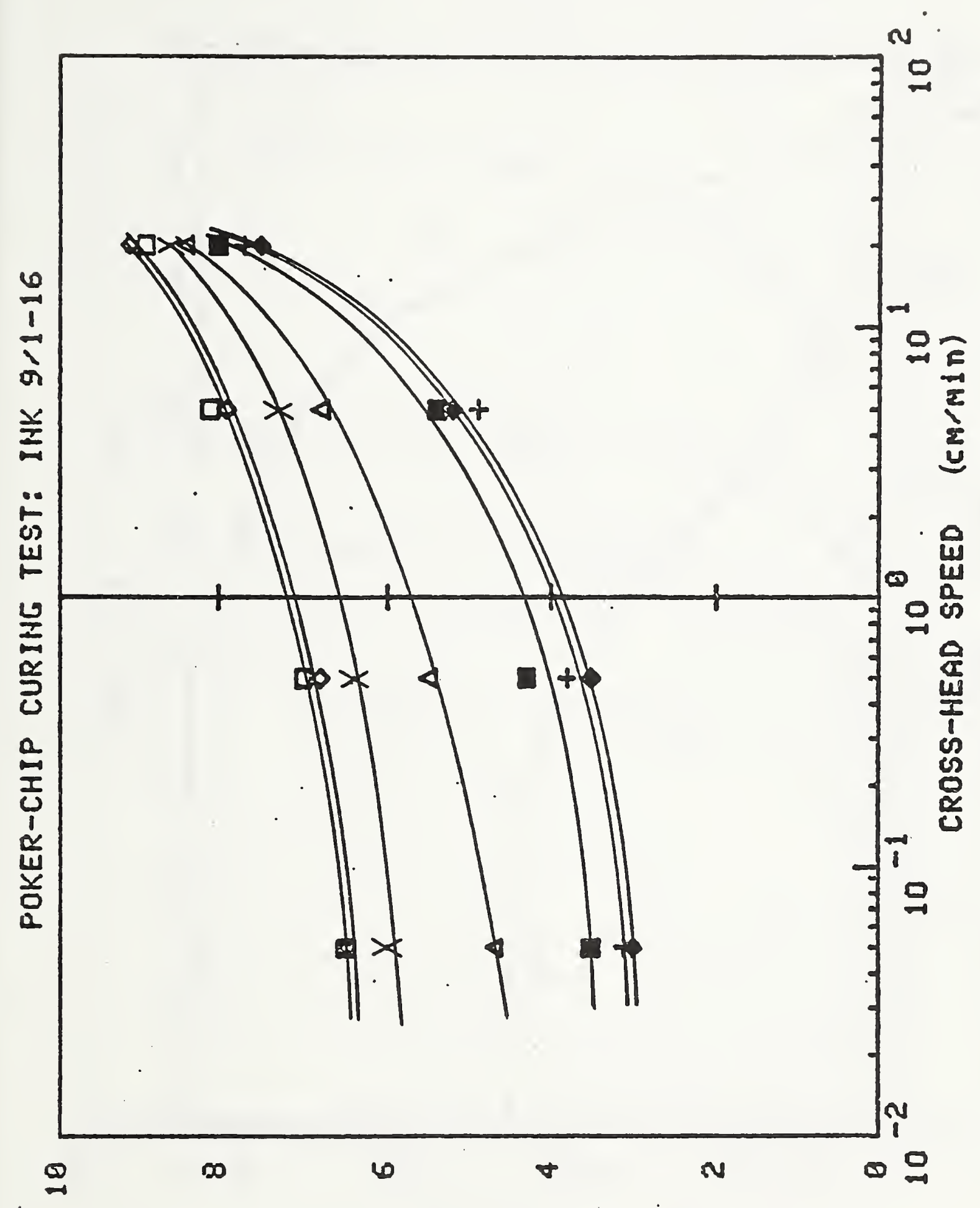

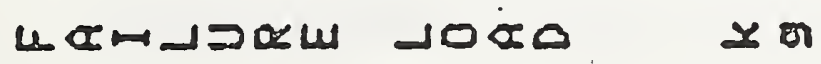


Figure 10

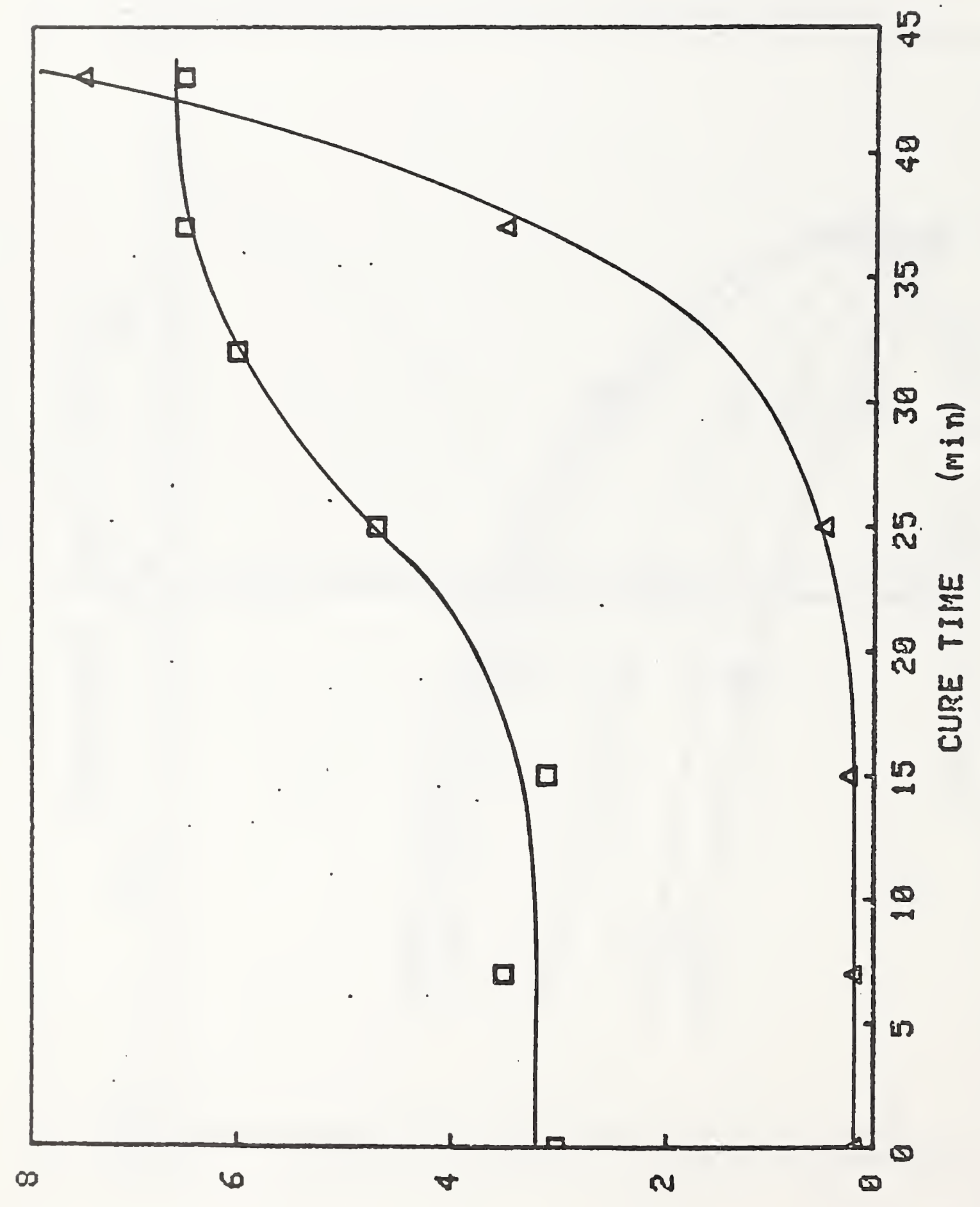


Figure 11

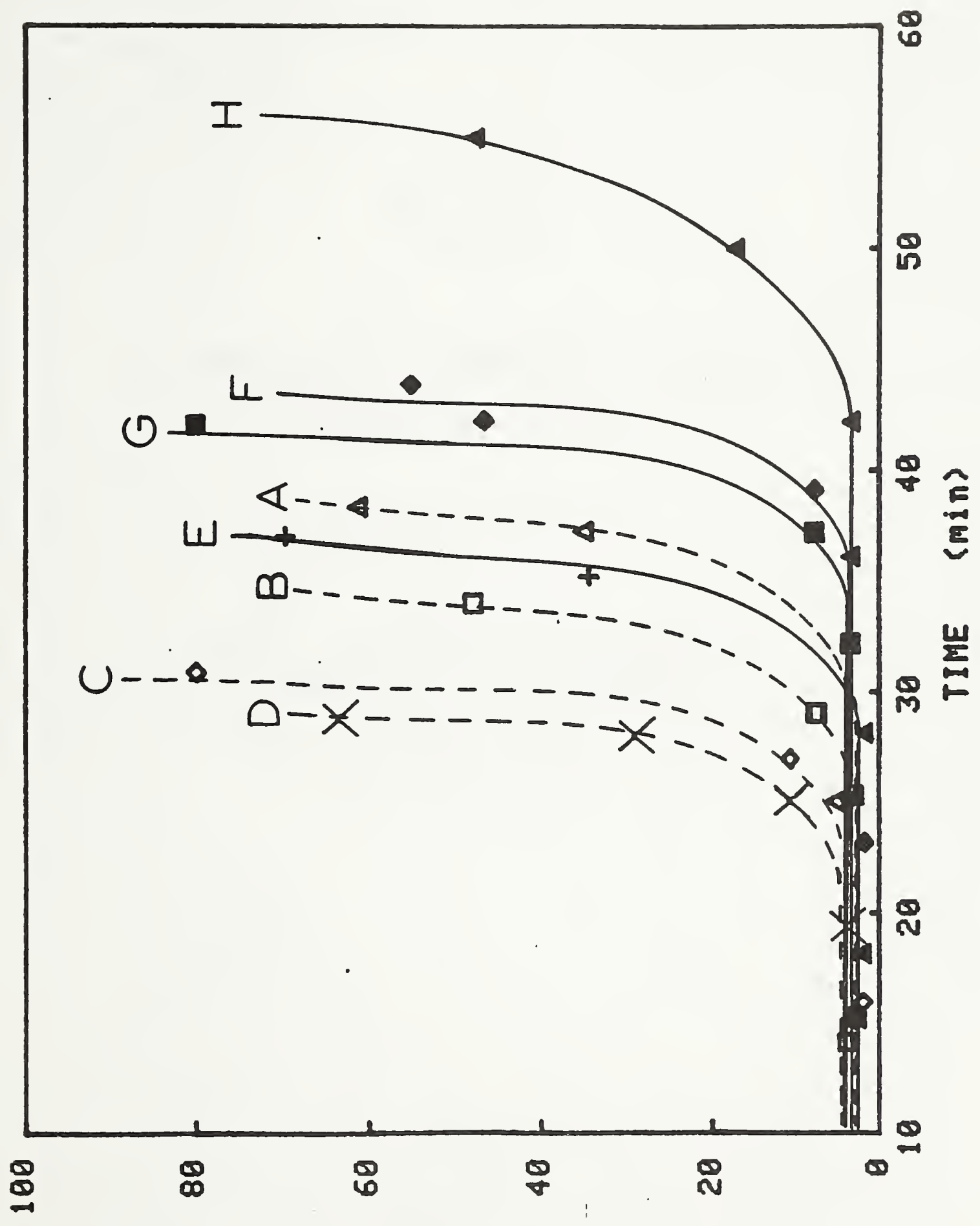





\author{
APPENDIX \\ CURE MONITORING OF THERMOSETTING POLYMERS BY AN \\ ULTRASONIC TECHNIQUE \\ Donald L. Hunston \\ Published in \\ REVIEW OF PROGRESS IN QUANTITATIVE \\ NONDESTRUCTIVE EVALUATION \\ Eds. D. Thompson and D Chementi \\ Plenum Press, New York, 1983
}



CURE MONITORING OF THERMOSETTING POLYMERS BY AN ULTRASONIC TECHNIQUE

\author{
Donald L. Hunston
}

National Bureau of Standards

Polymer Division

Washington, D.C. 20234

\title{
ABSTRACT
}

In the fabrication of components with thermosetting polymers, an essential step is the proper optimization of the cure cycle. In the early phases of the cure the polymer must have the appropriate flow properties to assure the proper wetting, spreading, and forming. It must then harden without excessive build up of residual stresses and flaws or the loss of adnesion at any interfaces that are present. To complicate the situation further, many applications such as composites, adhesives, paints, and protective coatings involve thin films whose cure behavior is significantly different than that for bulk samples. To help address this problem, an ultrasonic shear wave propagation technique has been developed. It is a laboratory device that measures the dynamic shear properties of a thin film in a way which is both nondestructive and nonperturbing to any chemical reactions that may be occurring. The applicability of this test method was demonstrated with cure studies on two nodel systems: one based on tung oil the other based on an epoxy resin.

\section{INTRODUCTION}

In recent years the use of polymers, reinforced with either fibers or particles, has undergone rapid expansion and as a result problems related to the fabrication of these materials have acquired major importance. The polymers involved are often thermosetting resins, that is, low molecular weight materials which polymerize or cure when heated. The low molecular weight of the starting materials means that they are liquids at room temperature or slightly above room temperature. As a consequence, 
the materlals will be fluid during the initlal stages of cure and this is crucial to obtain the proper wetting of the reinforcing agent, spreading at interfaces and into the corners of molds, and leveling of free surfaces. The success of these processes requires the viscosity to remain in the proper range for the appropriate time period. As the temperature is increased the viscosity initially falls but then rises again as the polynerization reactions initiate and proceed. Consequently, the proper thermal cycle is essential if good results are to be obtained.

As the polymer cures, it also acquires an elastic character which increases as the polymerization proceeds. Since polymerization is generally accompanied by shrinkage, this elasticity leads to a build-up of internal stresses within the polymer. If the reaction proceeds slowly, the internal stresses are less and the ability of the polymer to flow and thereby relieve these stresses is greater. Clearly, this means fewer problems, however, the slower the polymerization, the longer it takes to make a part and this affects productivity. The polynerization reactions also influence the properties of the final material since they control the molecular network that is formed. This network plays a major role in determining the modulus, fracture energy, and other important properties of the polywer. Even with identical starting materials the application of different cure schedules can produce very different final products. Consequently, the proper selection of the curing.times and temperatures is a crucial step to achieving high productivity.

In light of these considerations, there is a need to develop nondestructive methods for monitoring and studying cure, i.e. the liquid-to-solid conversion in thermosetting materials. Wnat makes. this particularly difficult is that many of the applications involve thin layers or films and the behavior of such samples generally can not be predicted from measurements on bulk specimens. In response to this need a number of dielectric and spectroscopic techniques have been developed. Although these methods are very useful, it is sometimes difficult to interpret the results in terms of the mechanical properties that determine performance. As a result this paper seeks to augment the existing measurenent methods with a new technique which can nondestructively determine the mechanical properties of thin films and monitor changes that occur during curing.

When studying the liquid to solid transition, it is the shear properties that are of most interest because the shear modulus undergoes very large changes: near zero for liquids, $10^{5}$ or $10^{6} \mathrm{~Pa}$ for the rubbery range and $10^{9}$ or $10^{10} \mathrm{~Pa}$ for glassy materials. obviously, this is a very sensitive parameter for monitoring. transitions. Noreover, the flow properties that are of interest usually involve the shear viscosity. To adapt the measurement of 
shear properties to the study of thin films, the use of ultrasonic shear wave propagation is advantageous because the attenuation of high frequency shear waves in many polymers is so large that a thin sample behaves as if it were infinitely thick; i.e., if a wave is generated at one surface of the film the amplitude of the displacement in this wave effectively goes to zero before the wave reaches the other surface of the film. This can greatly sinplify the analysis of the experimental system. A test based on this type of measurement therefore has a unique potential for addressing the problem of cure monitoring in thin films. It must be noted however that some uncured materials which respond as liquids or rubbers in most tests will respond as glasses at ultrasonic frequencies. Consequently, in these systems the liquid to solid conversion may produce only very small changes in the high frequency behavior. Although this represents a limitation on the approach, this paper will demonstrate that many important polymer systems can be examined with this technique.

A number of laboratories ${ }^{1-6}$ have developed experiments that use shear waves to measure the mechanical properties of organic liquids and polymers. One of these methods 4-6 is particularly appropriate for examining cure reactions because it maximizes the sensitivity of such techniques. This method involves a thin strip (with a rectangular cross section) of aluminum or quartz called a strip delay line (Figure 1). A ceramic transducer which is poled in the $z$-direction (placement of axes as shown in Figure 1) is attached to one end of the delay line. When the transducer is electrically excited, it generates a shear wave in the delay line. This wave travels in the $\mathrm{x}$-direction but has particle displacements in the z-direction. When the delay line is coated with a thin film of the sample, the wave in the delay line generates a corresponding shear wave in the coating. Although the attenuation of the wave in the coating is too large to observe this wave directly, Its generation changes the wave in the delay line: there is a significant increase in attenuation and a small decrease in velocity as measured along the length of the delay line. If these changes are determined, they can be used to calculate the properties of the coating. In coating the delay line it is only the two major surface (top and bottom in Figure 1) that are of importance.

In previous work ${ }^{4-7}$ it has been shown that the delay line technique can be used to measure the mechanical properties of viscoelastic fluids. The purpose of this research is to extend that method to the study of curing. This paper represents a progress report on this work. The results from four aspects of this research will be reported here: (1) A useful modification of the equation was derived. (2) The experinental technique was modified to permit rapid and accurate attenuation measurements: (3) Several model polyter systems were exanined to demonstrate the usefulness of the techniques for cure monitoring. (4) Tests 
were performed to investigate the effects of only partially coating the delay line surface with the sample.

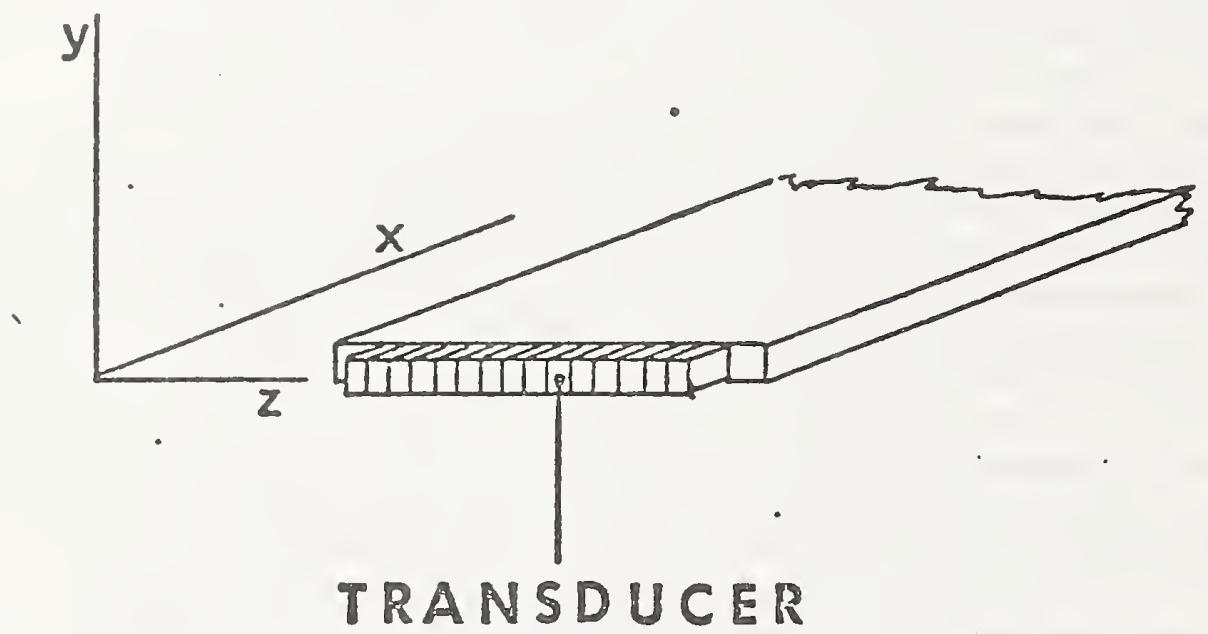

Figure 1: Schematic diagram of strip delay line

\section{ANALYSIS}

For the goals of the present program, i.e. cure monitoring, It is important that the experiment be able to follow the changes in mechanical properties that are associated with cure but it is not necessary that it be able to determine the exact values of the shear modulus. This is important because the delay line technique as originally developed $4-6$ requires both sides of the delay line to be fully coated with the sample if the shear modulus is to be determined. There are two reasons why it may be advantageous in some cases to coat only one side or part of one side with the sample. First, the background attenuation level, i.e. the attenuation in the delay line coated with the uncured sample, must not be too large or there will not be sufficient signal strength to follow the increase in attenuation associated with sample curing. This background attenuation is less if less of the surface area is coated. Second, when the sample is liquid during any phase of the cure, it is easier to prevent this liquid from flowing off the delay line surface if the delay line is mounted horizontally and only coated on the top surface.

Although important information can be obtained without calculating the exact values of the shear modulus, it is certainly 
desirable if this calculation can be made particularly when trying to establish relationships between curing and molecular level events. As a result the present study is addressing this goal. For the case where one side of the delay line is fully coated with the sample an analytical solution is possible and this development will be presented later in this section. For the case of a delay line with only a partial coating on one or both sides, however, it is not clear how to model this situation. The major uncertainty concerns what happens to the wave as it passes from the uncoated section into the coated section and vice versa. In the extreme case where the discountinuity between the coated and uncoated sections is large, a significant fraction of the wave's energy may be reflected back from the discontinuity. This obviously complicates the analysis. In most cases however this situation can be detected by the appearance of additional peaks in the echo pattern on the oscilloscope. In general the noise level would permit the detection of an additional reflection whose amplitude is $4 \%$ or more of the major echo. To date no detectable peaks of this type have been found with the samples tested here.

In the absence of a general analytical treatment for the partially coated delay line, the present study addresses this question empirically by comparing results for a delay line with various fractions of the surfaces coated. A major objective is to evaluate the simplest hypothesis that can be proposed, i.e., the magnitude of the change produced by coating the delay line is directly proportional to the fraction of the surface area that is coated. For example, this hypothesis would suggest that coating the delay line on only one side would produce changes that are half as large as those produced by fully coating the delay line on both sides.

For the special case of a delay line fully coated on one side, the situation will be modelled analytically. A detailed discussion of the assumptions and approximations that must be made to implement the delay line technique have been given elsewhere 4-7 $^{4}$ and, consequently, will not be repeated here. To facilitate this analysis however a brief review of the original derivation 4,6 will be made. The model for that analysis was an Infinite plate of thickness $2 b$ with a viscoelastic material on both sides (see Figure 2). A coordinate system was established with the plate surfaces at the planes $y=b$ and $y=-b$. A shear wave was propagated in the plate in the positive $x$ direction with displacement, $w$, in the $z$ direction and this wave generated a corresponding shear wave in the viscoelastic material. This wave travels away from the plate at an angle $\psi$ (the propagation velocity in the plate must be greater than that in the viscoelastic material). The three different regions in the model, Figure 2, were designated with the subscripts 0,1 , and 2 respectively, and the problem was treated as 2 dimensional (independent 
of z).

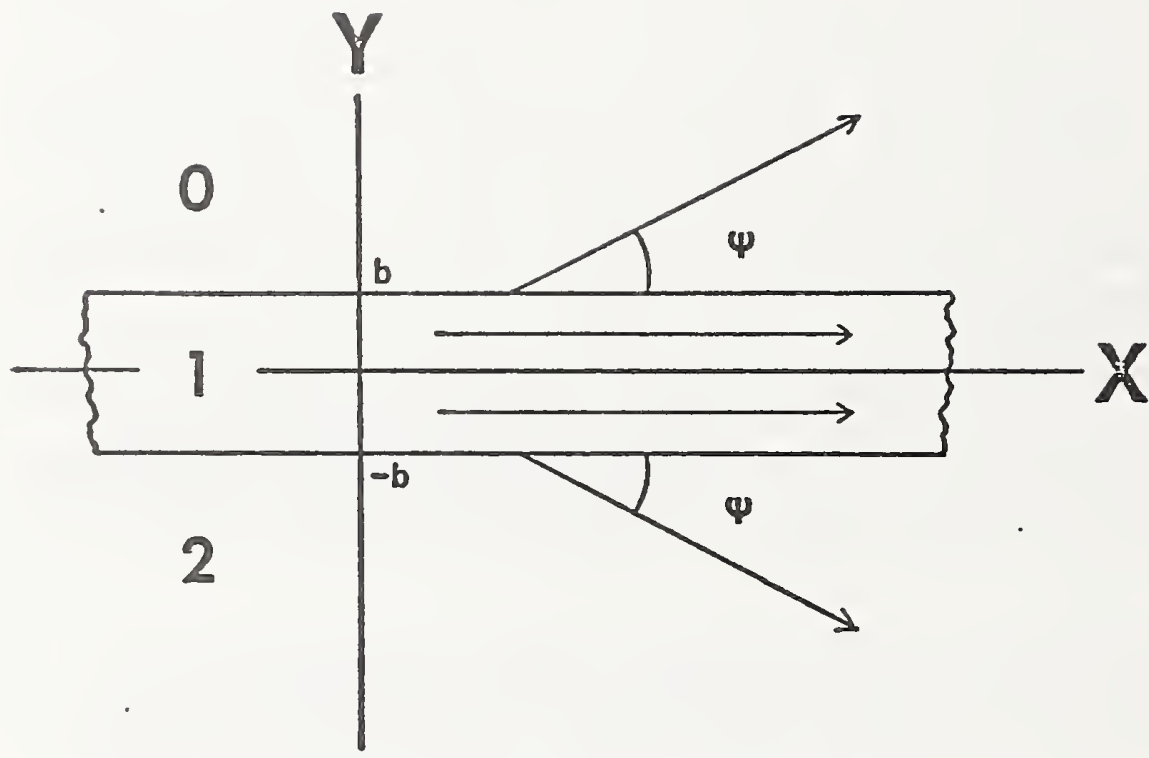

Figure 2: Placement of axis in infinite plate model with direction of wave propagation indicated. Displacement is perpendicular to $x-y$ plane.

By noting the direction of wave propagation and the fact that both the plate and the surrounding material will damp the wave motion, the equations for the displacements were simplified to

$$
\begin{aligned}
& w_{0}=H_{0} e^{\perp \omega t} e^{-n_{0} y} e^{-m_{0} x} \\
& w_{1}=e^{\perp \omega t}\left(E_{1} e^{n_{1} y}+F_{1} e^{-n_{1} y}\right) e^{-m_{1} x} \\
& w_{2}=H_{2} e^{\perp \omega t} e^{-n_{2} y} e^{-m_{2} x} .
\end{aligned}
$$

where $E, F$. and $H$ are constants, $t$ is time, $\omega$ is the angular frequency (in radians/sec), and $\mathrm{m}$ and $\mathrm{n}$ are the complex propagation constants for the $x$ and $y$ directions respectively. Each propagation constant combines a real part which gives the amplitude attenuation (in nepers/cm) and an imaginary part which is equal to the angular frequency divided by the appropriate velocity.

From the wave equation 


$$
m^{2}+n^{2}+\frac{\omega^{2} \rho}{G^{*}}=0
$$

where $\rho$ is the density, and $\dot{G}^{*}$ is the complex shear modulus for the material in which the wave is traveling. The shear modulus is composed of the shear storage modulus, G, which measures the eiastic component of the response and the shear loss modulus, $G$ ", which measures the viscous component of the response

$$
G^{*}=G^{\prime}+i G^{\prime \prime}
$$

To solve this problem it was necessary to relate $\mathrm{G}^{*}$ o to the behavior of the wave in the plate. This was done by noting that both the displacement and the stress must be continuous at the plate surface. The only non-zero stress in this model is $\tau_{y z}$, the shear stress acting in the z-direction at the plate surfaces.

$$
\tau_{y z}=G^{\star}\left(\frac{\partial w}{\partial y}\right)
$$

As a reference state the case where the medium in regions 0 and 2 is air was chosen. For this situation $\tau_{y z}$ could be taken as zero and since the plate thickness was small (less than half a wave length) only the pure shear mode of wave propagation was possible in the plate, i.e. $\mathfrak{n}_{1}=0$. This is the well-known result found by Meeker and others. 8 The value of $m_{1}$ for that case was designated M.

The problem of the plate in a linear viscoelastic material was then solved using the conditions of symmetry and continuity of stress and displacement at the interfaces. As outlined in references 4 and 6 , the result was

$$
G_{0}^{*}=\left(\frac{\omega^{2} \rho_{0}}{2 m_{1}^{2}}\right)\left[-1+\left(1-\frac{4 m_{1}{ }^{2} A^{2}}{\omega^{4} \rho_{0}^{2}}\right)^{\frac{3}{2}}\right]
$$

where

$$
A=\frac{-\omega^{2} \rho_{1} n_{1}\left(1-e^{2 n_{1} b}\right)}{M^{2}\left(1+e^{2 n_{1} b}\right)}
$$

and

$$
n_{1}=M^{2}-m_{1}^{2}
$$

Consequently, $\mathrm{G}_{0}^{*}$ can be calculated if $M, \mathrm{~m}_{1}, \rho_{0}, \rho_{1}, 2 \mathrm{~b}$, and $\omega$ are determined.

These equations are complicated and difficult to use; however, In many cases it was found that the addition of a coating to the delay line produces only a small change in the $x$ component of the propagation constant, 1.e. $\left(M-m_{1}\right) \leq 0.3(1+i)$, and under these 
conditions it was shown 4 that the equations could be dramatically simplified. These simplified equations were written in terms of the characteristic shear mechanical impedance, $\mathrm{Z}^{*}$, and the result was

$$
z_{0}^{*}=2 b z_{1}^{*}\left(M-m_{1}\right)
$$

where

$$
z^{*}=\left(\rho G^{*}\right)^{\frac{1}{2}}
$$

Although not developed in the original derivation, it is relatively simple to rewrite these equations in a more useful form by splitting the change in the propagation constant into a change in attenuation, $\Delta$, and a phase shift, $\phi$.

$$
\left(M-m_{1}\right)=\Delta+i \phi
$$

Equations (10) and (11) can then be combined to give

$$
G_{0}^{1}=B\left(\Delta^{2}-\phi^{2}\right) / \rho_{0}
$$

and

$$
G_{0}^{\prime \prime}=B(2 \Delta \phi) / \rho_{0}
$$

where

$$
\mathrm{B}=\left(2 \mathrm{bz}{ }_{1}^{*}\right)^{2}
$$

It is interesting to note that both $\Delta$ and $\phi$ must generally be determined before $G_{0}^{*}$ can be calculated; however, if the phase shift is significantly smaller than $\Delta$, equation (13) can be approximated as

$$
G_{0}^{1}=B \Delta^{2} / p_{0}
$$

Consequently, when the ratio $\phi / \Delta$ is significantly less than one, the elastic properties can be determined directly from attenuation measurements.

With the information above in mind it is now possible to address the case where region 2 (Figure 2 ) is air while region 0 is viscoelastic material. This means the stresses are zero at $y=-b$ which results in the reltionship

$$
F_{1}=E_{1} e^{-2 n_{1} b}
$$

If the conditions of continuity of stress and displacement are then applied for the plane $y=b$, the derivation proceeds in exactly the same manner as in the original analysis. By following the steps outlined in references 4 and 6 , equations can be developed for this new model. Such an analysis gives relationships that are identical to equations (7-9) except that the quantity $2 \mathrm{n}_{1} \mathrm{~b}$ in 
expresston ( 8 ) Is replaced by $4 n_{1} b$. Since this is the only place $b$ appears in the equations, it means that a very interesting result is obtained, $1 . e .$, a delay line coated on only one side is equivalent to a line twice as thlck coated on both sides. In retrospect this conclusion is not so surprising for if the model for the line coated on both sides (Figure 2) is examined, it will be noted that the shear stress on the $y=0$ plane is zero. Consequently, the displacement equations for this model would satisfy the boundary conditions for a plate coated on only one side if the thickness were taken as $b$, one surface were placed at $y=0$, and the other at $y=b$. Another interesting observation can be made from these results. For the case where only one side of the plate (thickness $2 \mathrm{~b}$ ) is coated, equation (15) becomes

$$
\mathrm{B}=\left(4 \mathrm{bz} z^{*}\right)^{2}
$$

A comparison of equations (15) and (18) shows that under conditions where these expressions apply, $\Delta$ and $\phi$ are only half as large when one side is coated as compared with the results when both sides are coated. Consequently, the simplistic hypothesis made earlier is in fact correct for this special case.

\section{EXPERIMIENTAL SECTION}

The apparatus utilized in these tests is similar to that described previously. It employs a quartz delay Ine that is $9.42 \mathrm{~cm}$ long, $2.54 \mathrm{~cm}$ wide, and $0.185 \mathrm{~cm}$ thick (Figure 1). A ceramic transducer which is mounted at one end of the line is used to generate and monitor the shear wave at a frequency of $2.900 \mathrm{MHz}$. The experiments were conducted using the pulse-echo technique. A gated sine wave generator is used to produce a short burst of sine waves. A minimum of 30 cycles is used to assure that the predominant response of the materlal corresponds to a sinusoidal disturbance at $2.9 \mathrm{MHz}$. The transducer converts this signal into mechanical wave motion that travels down and back the length of the delay line. As this packet reflects back and forth between the ends of the delay line, each reflection from the end connected to the transducer generates an electrical signal in the transducer that can be fed through an amplifier to an.oscilloscope. This signal provides a means to monitor the wave motion in the delay line. The oscilloscope display, Figure 3, Is a series of sine wave packets that show the characteristic exponential decay as a function of time (or distance traveled). Thie spacing of the packet corresponds to the round trip travel time down and back the length of the delay line. When the surface of the line is coated with a sample, there is an Increase in the rate of decay (or attenuation per unit distance traveled) and a slight increase in the separation of the packet. 


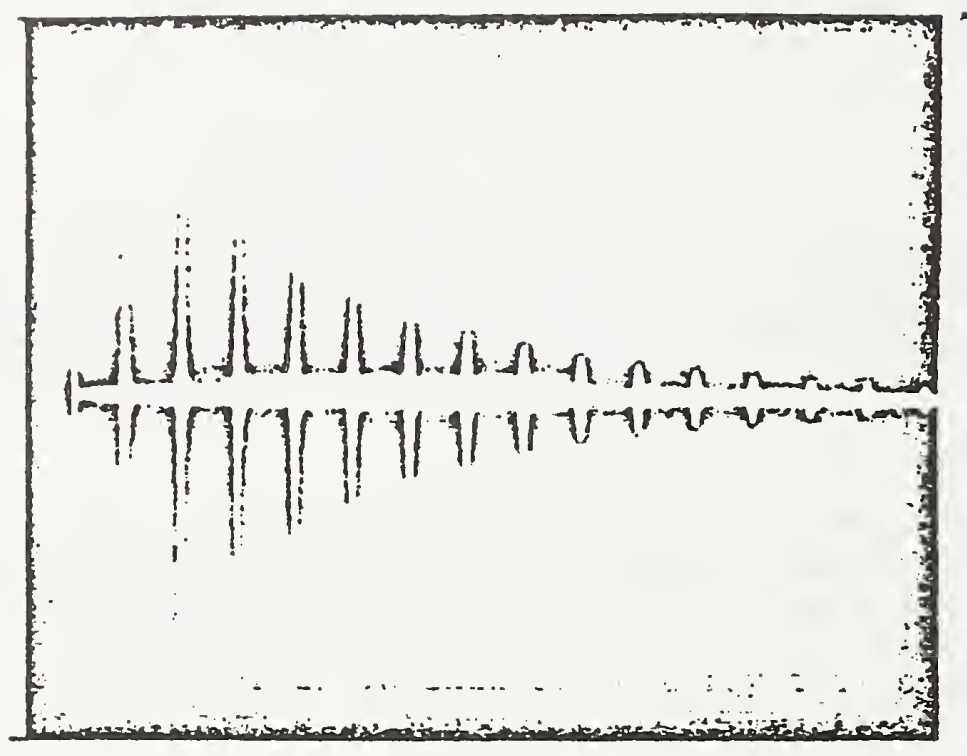

Pigure 3: Oscilloscope display of a typical echo pattern for an uncoated delay line.

The change in attenuation can be determined simply by monitoring the height of a single packet; however, it is much more accurate and reliable to monitor the heights of a series of packets and fit this data to an exponential decay. To perform this task rapidly the technique used in this work was to combine the transducer output signal with a negative DC voltage. The DC signal was then adjusted until the top of a given packet was suppressed to the base-Ilne. This DC voltage provided a measure of the packet height (or wave amplitude in the packet). The voltage for a series of packets was determined this way and digitized directly into a minicomputer which determined the best fit exponential decay and plotted the results on a display terminal (Figure 4). In this way very accurate attenuation measurements could be obtained in only a few seconds.

For most of the work described in this paper only attenuation measurements were made. The changes in velocity that must be determined to provide meaningful phase shift measurements are very small (less than 1 part in $10^{5}$ ) and thus specialized equipment is needed. Recently, this equipment was assembled and the apparatus was adapted to implement the echo overlap technique for velocity measurements. As a result, a few of the 


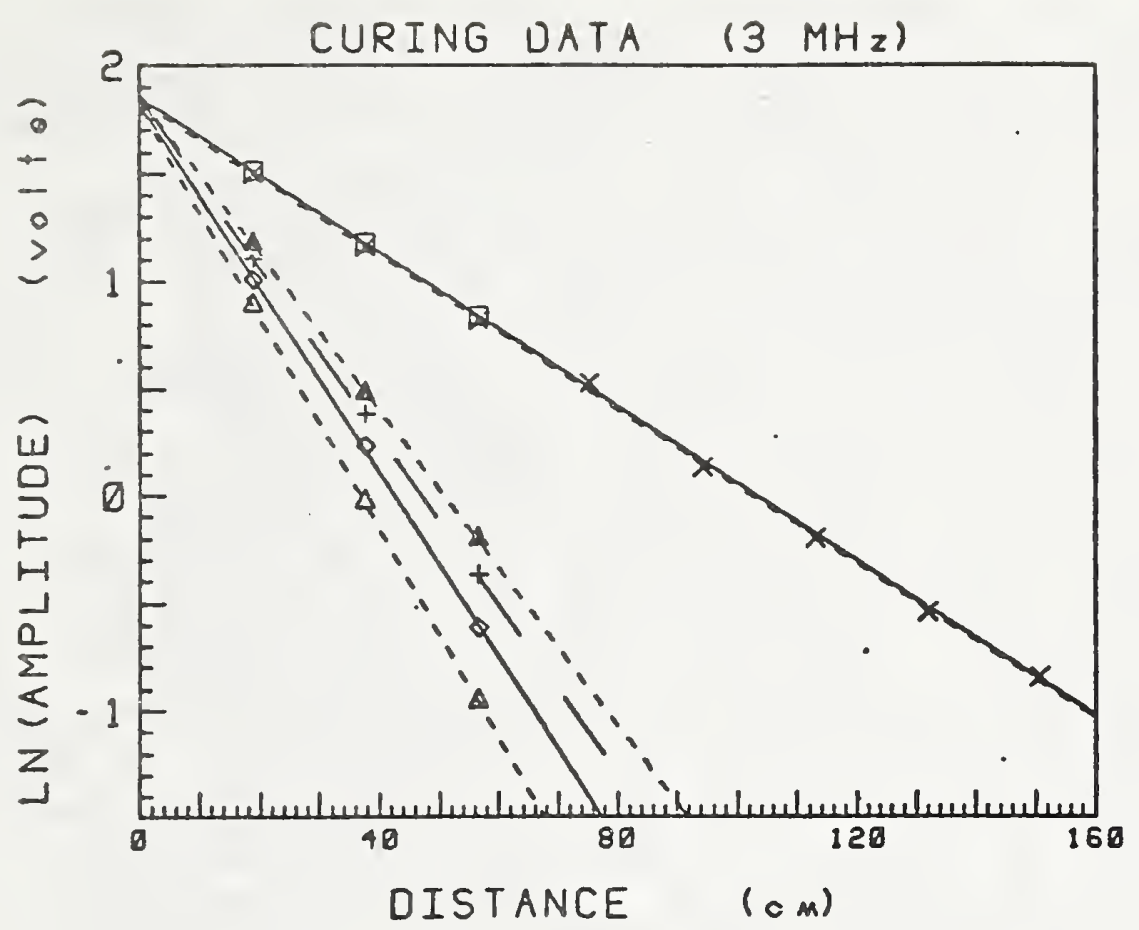

Figure 4: A graph of the natural logarithm of the wave amplitude vs. distance traveled in the delay line and the best fit straight line for each data set: blank line before $\square$ and after $X$ curing experiment, $I$ c⿴l of line coated with tung oil system and cured for 0 min. \& , 133 min $t$, $443 \min \gamma$, and $3000 \min \triangle$.

most recent tests have included some efforts to measure changes in both velocity and attenuation. Details of the echo-overlap technique can be found in references $5,6,9$, and 10 .

The work reported here employed two different model polymer systems for cure rate studies and a third polymeric material to help evaluate the technique itself. The criteria for selecting the model systems were that they be convenient to test and yet be representative of the types of polymeric materials that are of practical importance. The first system tested was based on natural drying oils (tung oil) and contained about $80 \%$ inorganic filler. These unsaturated oil systems polymerize when exposed to air in thin films, particularly when heated, and consequently, they are used in a number of applications including printing inks ${ }^{11}$. As a model system for study, this material has the advantage that it will cure at room temperature with a relatively slow curing rate so the transition is easy to follow experimentally. Moreover, the cured film can be removed from the delay line quite easily at the end of the experiment and this is very useful for such tests. 
The second model system examined in this work was an epoxybased formulation. As a result, it represents an example of an extremely important type of comerical polymer. In this particular formulation, 12 a standard epoxy resin was reacted with methacrylic acid to form Bisglycidyl-methacrylate of Bisphenol-A, Bis-GMA. This material can be cured through its reactive methacrylate endgroups using a free radical polymerization initiator (about 0.5\% by welght benzoyl peroxide, BPO). Although BPO will induce polymerization in this material, its action is slow at room temperatures. Consequently, an accelerator, Bis-(N,N-2-hydroxy propy 1) p-toluidine or DHPPT, was added. In addition some triethylene glycol dimethacrylate (TEG DMA) was included in the formulation to lower the initial viscosity ( 3 parts by weight TEG DMA for every 7 parts by weight of Bis GMA). The advantages of this system as a model for cure studies are that it cures at room temperature and the rate of cure can be varied by changing the concentration of the accelerator. For the present work 2 different accelerator concentrations were examined $(0.25 \%$ and $0.35 \%$ by weight). The presence of oxygen inhibits the initiation of the reaction by converting the free radicals that are formed into less reactive species. As a result, all tests with this system were carried out in a nitrogen atmosphere. Nevertheless, some oxygen was always present in the solutions initially and this produced an induction period in which the initiation of polymerization was delayed until all of the available oxygen has reacted.

For both model systems the cure experiments were performed at room temperature $\left(20^{\circ} \mathrm{C} \pm 0.2\right.$ or better short term) using a film thickness of approximately 100um. Experiments indicate that this thickness was sufficiently large to make the results independent of film thickness. With regard to the size of the area on the delay Iine. surface that was coated, however, both of the model systems have a high background attenuation (the attenuation level with the delay line coated with the uncured sample). As a result all of the experiments were performed with only part of one side of the line covered. The area chosen was at the end of the line not connected to the transducer and extending $1.0 \mathrm{~cm}$ down the line.

The third model polymeric system tested in this study was used to empirically compare the results for a partially coated delay line and those for. a fully coated delay line. This material was a highly plasticized polyvinyl chloride (PVC). It was prepared using 100 parts of plasticizer (dioctyl phthalate), 20 parts of polyvinyl chloride, and 2 parts of stabilizer (dibutyltin maleate). The ingredients were mixed at $170^{\circ} \mathrm{C}$, poured onto a flat surface to form sheets and allowed to cool slowly. The sheets were aged for 24 hours before testing. This material was selected because it is soft enough to deform and give good contact with the delay line surface and yet is stiff enough to 
permit easy handling and accurate measurement of the area covered. Another advantage of this farmulation is that it has high damping properties and thus the phase shift can readily be measured.

The data obtained for the fully coated delay line can be used to calculate a dynamic shear modulus for this material. Although the numbers obtained are within the general range expected based on extrapolating lower frequency data generated with another measurement technique, a quantitative comparison is not possible because no independent measurement of the mechanical properties are available at $3 \mathrm{MHz}$. Consequently, this sample can not be used to test the validity of the technique itself. Fortunately, two independent laboratories 6,7 have now examined the delay line method extensively and found it to provide an accurate measurement technique for viscoelastic properties and thus the absence of $3 \mathrm{MHz}$ data for this material is not a serious drawback. The more important question is how the data for a partially coated line compares with that for the fully coated line. These tests were performed by pressing the PVC material against various fractions of one or both sides of the delay line. With these results the simple hypothesis mentioned earlier can be examined. The measured values for the increase in attenuation and phase shift were simply scaled up by dividing by the fraction of the surface area that was covered to give predictions for $\Delta$ and $\phi$ in a fully coated line. These numbers were then compared with measurements actually made on the fully coated delay line. The tests also made it possible to examine the applicability of the analysis for the line coated on only one side since the results for this situation could also be compared with the data for the fully coated line.

\section{RESULTS AND DISCUSSION}

Typical results for the curing experiment with the tung oil based polymer system are given in Figure 4 which shows the natural logarithm of the wave amplitude as a function of the propagation distance for the delay line in air, and for the coated line at selected cure times. The slope of each line gives the average attenuation per $\mathrm{cm}, \alpha$. Figure 5 shows a plot in which the points give values of a measured as a function of curing time for this system. Initially there is a rapid increase in a but then it begins to level-off and approach a limiting value. Actually, careful measurements show that a continues to increase slowly for many days, but since it is only the initial stages of cure that are of interest here, an effective short term limit, $a_{\infty}$, will be defined on the basis of the data in Figure 5.

In many polymerization studies it is found that changes in various properties during the early stages of cure can be described with a first order rate equation. To examine this possibility, the 


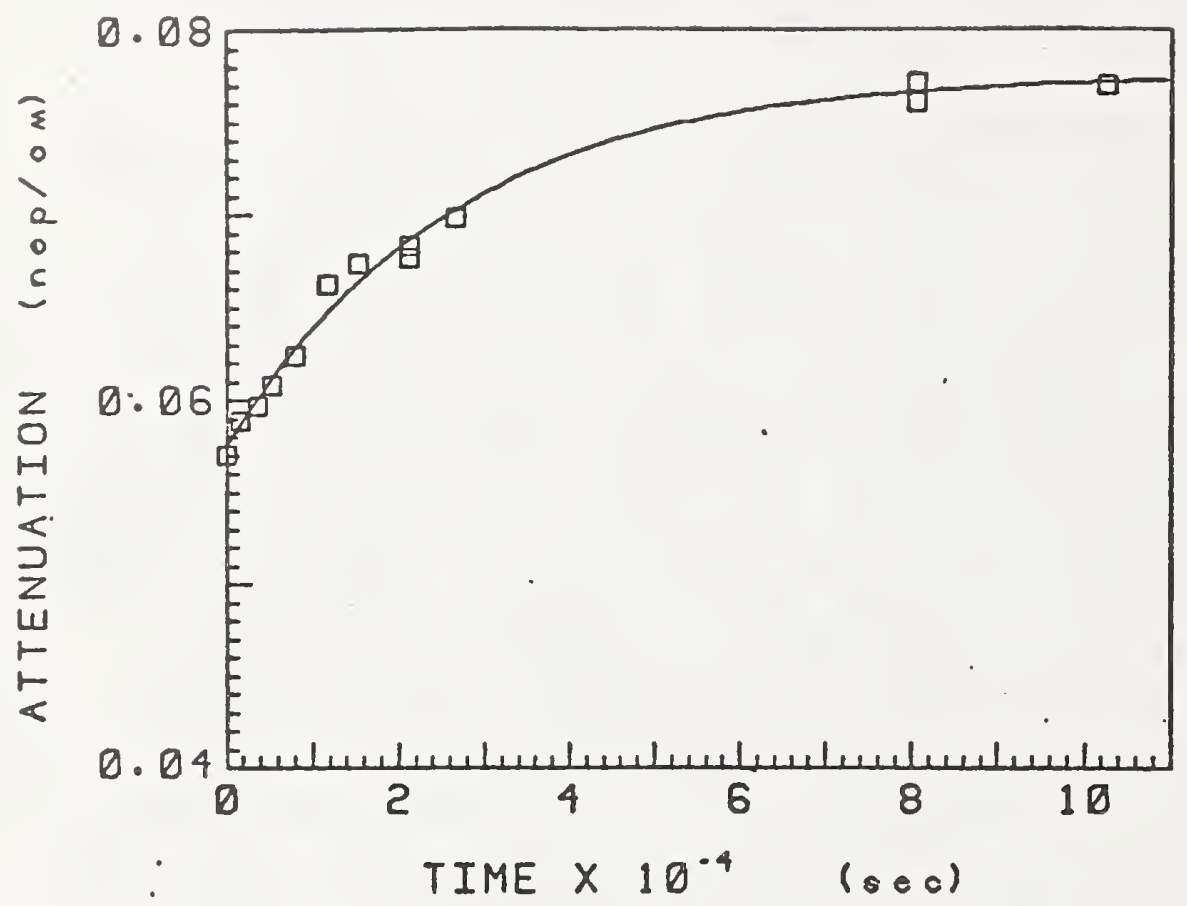

Figure 5: The average attenuation per $\mathrm{cm}, \alpha$, as a function of curing time for tung oil system ( $1 \mathrm{~cm}$ of line coated).

data in Figure 5 were plotted as $\log \left(\alpha_{\infty}-\alpha\right)$ vs. time, and the best fit straight line was fit to this data. The result is shown in Figure 6 , and as can be seen, this line provides a reasonable description of the data. The negative of the slope of this line, $k$, provides a relative measure of the rate of change in mechanical properties. Another indication of the fit provided by this model is the curve in Figure 5 which represents the prediction for the first order equation. The agreement between the data points and the calculated curve is very good.

The cure of the epoxy system can be examined in the same way. Figure 7 shows a plot of a vs. time for two formulations. As expected, the data show an initiation period as well as the cure kinetics. The transition protions of the data can be analyzed in a plot of $\log \left(\alpha_{\infty}-\alpha\right)$ vs. time. As shown in Figure 8 , the first order equation again provides a reasonable fit to the data. If a horlzontal line corresponding to the initial value of $\log \left(\alpha_{\infty}-\alpha\right)$ is shown in Figure 8, then the intersections of this line and the first order equation lines provide a measure of the induction perlod, $t_{0}$. As can be seen in this figure, the higher concentration of accelerator not only increases the relative cure rate but also shortens the induction period. This can be understood by 
notlng that the accelerator not only speeds-up the cure rate but also the rate at which the oxygen initially dissolved in the sample is used-up. Since rapid polymerization does not begin until the oxygen has reacted, additional accelerator would be expected to significantly shorten the induction period.

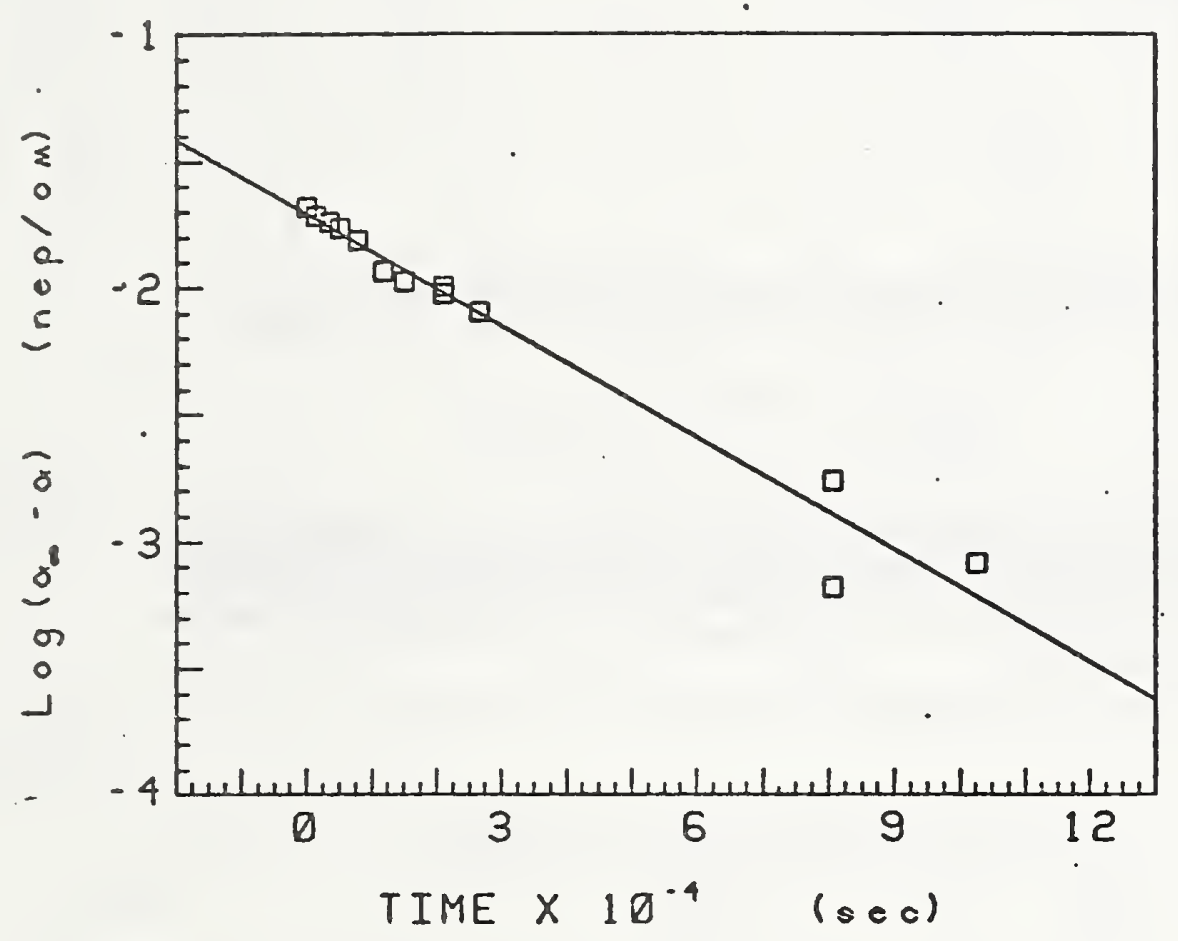

Figure 6: First order data analysis plot for data in transition region in Figure 5. 
$16{ }^{\circ}$

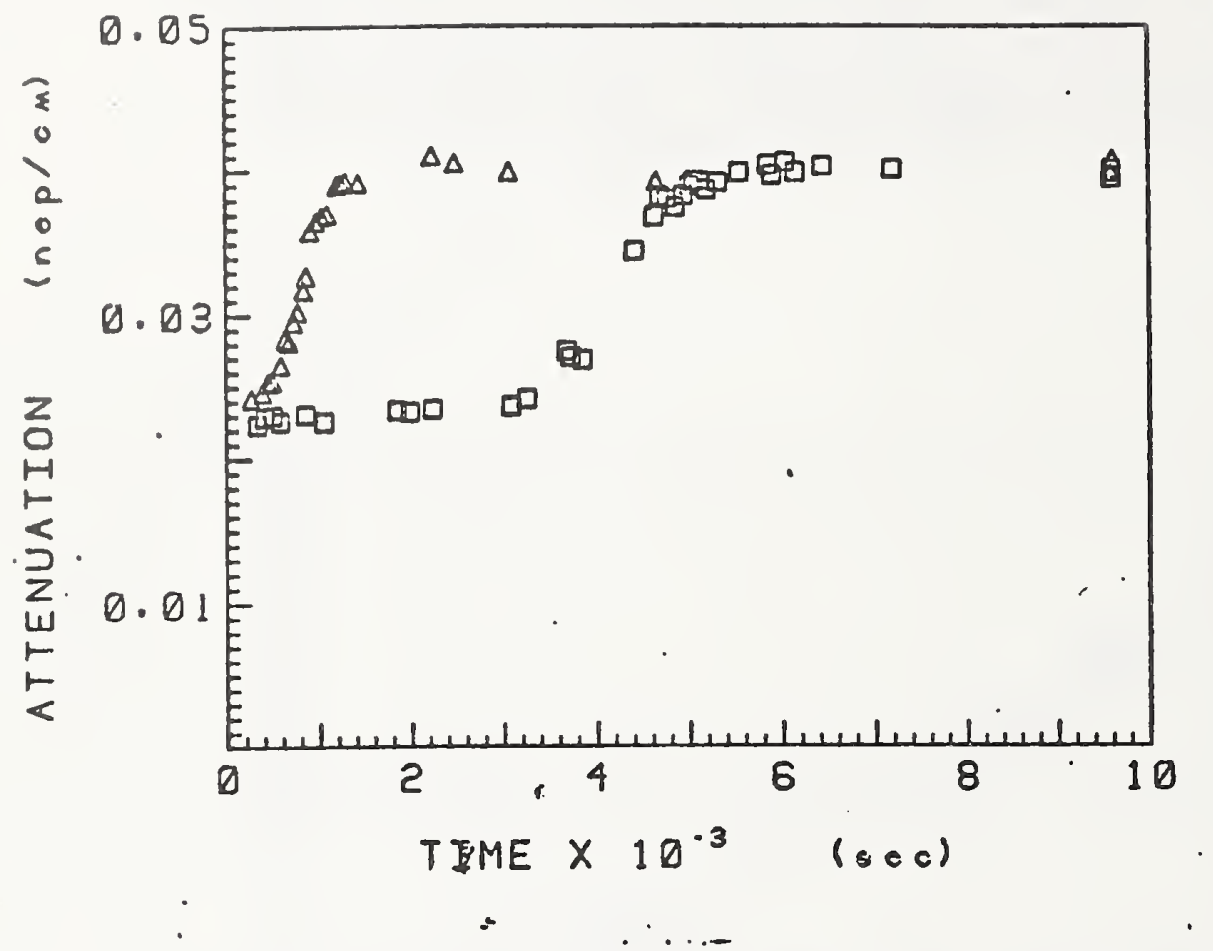

Figure 7: The average attenuation per $\mathrm{cm}, \alpha$, as a function of curing time for epoxy based systems with accelerator concentrations of $0.25 \% \square$, and $0.35 \% \triangle(1 \mathrm{~cm}$ of line coated). 


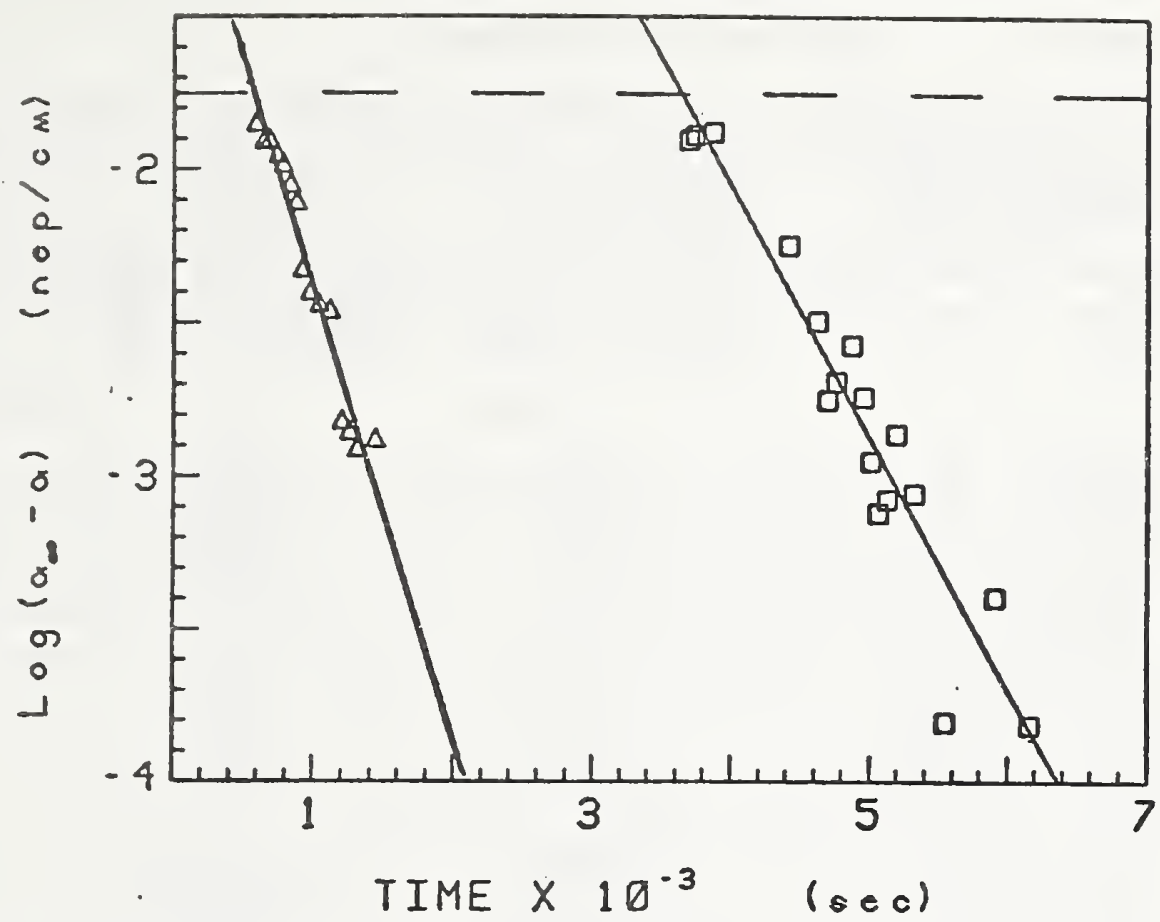

Figure 8: First order data analysis plot for data in transition regions in Figure 7. Dashed line is estimate for value of line with coating before initiation of cure.

The values of $k$ and $t_{0}$ for the three systems discussed above are given in Table $I$.

Table I Parameters from analysis of cure

\begin{tabular}{lcc}
\hline System & $\begin{array}{c}\mathrm{k}^{ \pm} \\
\left(\mathrm{sec}^{-1}\right)\end{array}$ & $\begin{array}{c}\mathbf{t}_{0}^{+} \\
(\mathrm{sec})\end{array}$ \\
\hline tung oil & $1.5 \times 10^{-5}$ & 0 \\
epoxy $/ 0.25 \%$ accelerator & $8.2 \times 10^{-4}$ & 3630 \\
epoxy $/ 0.35 \%$ accelerator & $1.5 \times 10^{-3}$ & 580 \\
\hline negative of slope of 1ines in Figures 6 and 8. & \\
+ from intersection of 1ines in Figure 8. &
\end{tabular}

These experiments clearly indicate the potential usefulness of this device as a cure monitoring tool even though the relationship between the measured quantities and the actual values of the shear modulus have not been established analytically for the partially coated delay 11ne. The results of the empirical tests 
to examine this relationship are shown in Table II.

Table II Results for PVC Material

\begin{tabular}{|c|c|c|c|c|c|}
\hline $\begin{array}{c}\text { Number of } \\
\text { Tests }\end{array}$ & $\frac{\% \text { Are }}{\text { Side }}$ & $\frac{\text { Covered }}{\text { Side } 2}$ & $\underset{\text { (ne }}{\Delta}$ & (cm) & $(\mathrm{rad} / \mathrm{cm})$ \\
\hline $\begin{array}{l}6 \\
5\end{array}$ & $\begin{array}{l}100 \\
100\end{array}$ & $\begin{array}{r}100 \\
0\end{array}$ & $\begin{array}{l}0.040 \\
0.041\end{array}$ & $\begin{array}{l}\text { to } 0.042 \\
\text { to } 0.044\end{array}$ & $\begin{array}{l}0.029 \text { to } 0.032 \\
0.029 \text { to } 0.031\end{array}$ \\
\hline $\begin{array}{l}1 \\
1 \\
1 \\
1 \\
1\end{array}$ & $\begin{array}{l}26.5 \\
46.7 \\
51.0 \\
73.2 \\
75.4\end{array}$ & $\begin{array}{l}0 \\
0 \\
0 \\
0 \\
0\end{array}$ & & $\begin{array}{l}0.043 \\
0.044 \\
0.043 \\
0.043 \\
0.043\end{array}$ & $\begin{array}{r}0.029 \\
. \quad 0.028 \\
0.031 \\
. \quad 0.029 \\
. \quad 0.030\end{array}$ \\
\hline $\begin{array}{l}1 \\
1 \\
1\end{array}$ & $\begin{array}{l}31.8 \\
53.1 \\
75.4\end{array}$ & $\begin{array}{l}31.8 \\
53.1 \\
75.4\end{array}$ & & $\begin{array}{l}0.044 \\
0.041 \\
0.041\end{array}$ & $\begin{array}{l}0.032 \\
0.030 \\
0.029\end{array}$ \\
\hline $\begin{array}{l}1 \\
1 \\
1\end{array}$ & $\begin{array}{l}100 \\
100 \\
100\end{array}$ & $\begin{array}{l}22.3 \\
46.7 \\
73.2\end{array}$ & & $\begin{array}{l}0.041 \\
0.042 \\
0.040\end{array}$ & $\begin{array}{l}0.030 \\
0.028 \\
0.030\end{array}$ \\
\hline
\end{tabular}

This Table lists values of $\Delta$ and $\phi$ that were either measured on, converted to, or predicted for a fully coated line, i.e. the measured values were divided by the fraction of the delay line surface that was coated.

Two features of these results should be noted. First the data for the fully coated line can be compared with that of the line coated on only one side to test the applicability of the analysis developed in this paper. Table II shows that there is excellent agreement between the values obtained with the two geometries. From the data provided by these two cases, the best estimates for the correct values of $\Delta$ and $\phi$ are $0.042 \pm 0.002$ nepers $/ \mathrm{cm}$ and $0.030 \pm 0.002$ radians $/ \mathrm{cm}$, respectively. The uncertainties in these results are consistent with what is expected based on previous work 6 in view of the temperature variations that are present here. The second feature of Table II that is of interest is a comparison between the best estimate values of $\Delta$ and $\phi$ and those predicted from the results of experiments on partially coated delay lines. The only indication of a difference between the two types of experiments is the trend that can be seen in the measurement of $\Delta$. The estimates for $\Delta$ are slightly larger when less of the delay IIne surface is coated. These varfations, however, are within the estimated 
experimental uncertainty and thus for these tests no significant differences were found between estimates based on experiments with a partially coated delay line and measurements on a fully coated delay Iine.

Obviously the limited data presented in Table II can not establish the validity of using a partially coated delay Iine to calculate a shear modulus. Such an assertion will require additional data on a wide variety of samples. Nevertheless, the data generated here represent a very encouraging first step and provide strong motivation for additional studies.

\section{CUNCLUSION}

A valuable tool for monitoring the cure of thin films of polymeric materials has been developed and demonstrated with several model polymer systems. The technique measures parameters that are related to the mechanical properties of the polymer film and changes in these parameters can be used to follow curing of the film. When the sample permits experiments to be conducted with a delay line fully coated on one or both sides, the actual value of the complex dynamic shear modulus can be determined. For experiments with a partially coated line, the data can be used to examine rates of cure and other important kinetic parameters and possibly the shear modulus as well. Initial experiments have been performed to empirically examine the relationship between the parameters measured by this technique and the complex dynamic shear modulus for the case of a partially coated delay line. These tests suggest that the relationship may be quite simple.

\section{REFERENCES}

1. A. J. Barlow, G. Harrison, J. Richter, H. Sequin, and J. Lamb, Electrical Methods for the Viscoelastic Behavior of Liquids under Cyclic Shearing Stress, Lab. Pract:, 10, 786 (1961).

2. W. P. Mason, W. O. Baker, H. J. McSkimin, and J. H. Heiss, Measurement of Shear Elasticity and Viscosity of Liquids at Utrasonic Frequencies, Physical Review, 75, 936 (1949).

3. C. J. Knauss, D. Leppo, and R. R. Myers, Viscoelastic Measurement of Polybutenes and Low Viscosity Liquids Using Ultrasonic Strip Delay Lines, J. Polym. Sci., Symposium No. 43, 179 (1973).

4. D. L. Hunston, R. R. Myers, and M. B. Palmer, A. Layered Waveguide Technique for Determination of the Viscoelastic Properties of Liquids and Deformable Solids, Trans. Soc. 
Rheol., 16, 33 (1972).

5. D. L. Hunston, C. J. Knauss, M. B. Palmer, and R. R. Myers, Viscoelastic Measurements of Poly(dimethylsiloxanes) and a Polystyrene Solution Using the Layered Waveguide Technique, Trans.Soc. Rheol., 16, 45 (1972).

6. D. L. Hunston, Determination of Viscoelastic Constants for Polymers Using Non-Dispersive Strip Delay Lines, PhD Dissertation, Kent State University, Kent, Ohio, 1969.

7. I. Koh, An UItrasonic Method for Measurement of Viscoelastic Properties of Polymeric Solutions, PhD Thesis, Rensselaer Polytechnic Institute, Troy, New York, 1977.

8. T. R. Meeker and A. H. Meitzler, Guided Wave Propagation in Elongated Cylinders and Plates in "Physical Acoustics", Vol.I, W. P. Mason, ed., Academic Press, New York, 1974.

9. J. E. May.Jr., Precise Measurement of Time Delay, I.R.E. Convention Rec., 6, Part 2, 134 (1958).

10. E. P. Papadakis, UItrasonic Phase Velocity by the Pulse-EchoOverlap Method Incorporating Diffraction Phase Corrections, J. Acoust. Soc. Am., 42, 1045 (1967).

11. D. L. Hunston, J. L. Rushford, W. R. Newitt, and B. A. Vaudreuil, Rheology of Cure for Intaglio Printing Inks, Organic Coatings and Plastics Preprints, 47, 513 (1982).

12. A. K. Banthia, I. Yilgor, J. E. McGrath, and G. Wilkes, Bis-Methacryloxy Bisphenol-A Epoxy Networks, Polymer Preprints, 22 (1), 209 (1981). 
U.S. DEPT. OF COMM.

SHEET (See instructions)

4. TITLE AND SUBTITLE

Relationships between Mechanical Properties and Performance of Inks

as the Basis for Quality Control Techniques: Part II

5. AUTHOR(S)

Donald L. Hunston and George W. Bullman

6. PERFORMING ORGANIZATION (If joint or other than NBS, see instructions)

NATIONAL BUREAU OF STANDARDS

DEPARTMENT OF COMMERCE

WASHINGTON, D.C. 20234

7. Contract/Grant No. $\mathrm{V}-0283-03$

8. Type of Report \& Period Covered Annual Report 1983

9. SPONSORING ORGANIZATION NAME AND COMPLETE ADDRESS (Street, City, State, ZIP)

U. S. Department of Treasury

Bureau of Engraving and Printing

Department of Research and Technical Services

Washington, D. C. 20226

10. SUPPLEMENTARY NOTES

Document describes a computer program; SF-185, FIPS Software Summary, Is attached.

11. ABSTRACT (A 200-word or less factual summary of most significant information. If document includes a significant bibliography or literature survey, mention it here)

This report reviews the progress of a joint program with the Bureau of Engraving and Printing (BEP) designed to study the mechanical properties of ink both before and during curing. The objectives are to develop quality control tests and guidelines for improved ink formulations. This report covers progress in a number of specific research areas. First, the development of a new cure test using a rubber mill to simulate some conditions on the press is discussed, and the use of this test to investigate the effects of temperature and film thickness is reviewed. Second, the optimization of viscosity tests and their. use to study premature curing of the ink in the fountain on the press is presented. The use of a nitrogen cover to retard unwanted curing is also examined with this test. Third, the development of the squeeze flow, poker-chip, and ultrasonic tests as ink cure monitoring tools is discussed. Finally, the examination of inks from the BEP quality control program is reviewed and a correlation between ink cure and performance is developed.

12. KEY WORDS (Six to twelve entries; alphabetical order; capitalize only proper names; and seporate key words by semicolons) curing; drying; intaglio ink; linseed oil; printing; rheology; tung oil; viscoelasticity; viscosity

13. AVAILABILITY

[X] Unlimited

$\square$ For Official Distribution. Do Not Release to NTIS

Order From Superintendent of Documents, U.S. Government Printing Office, Washington, D.C. 20402.

[X] Order From National Technical Information Service (NTIS), Springfield, VA. 2216I
14. NO. OF PRINTED PAGES

$$
54
$$

15. Price \$ 10.00 

